Article

\title{
Evaluation of Performance of Existing RO Drinking Water Stations in the North Central Province, Sri Lanka
}

\author{
Suresh Indika 1,2,3, Yuansong Wei ${ }^{1,2,3,4, * \mathbb{D}}$, Dazhou Hu ${ }^{1,2,3}$, Jegetheeswaran Ketharani ${ }^{5}$, Tharindu Ritigala $1,2,3 \mathbb{D}^{1}$, \\ Titus Cooray ${ }^{6}$, M. A. C. K. Hansima ${ }^{7}$, Madhubashini Makehelwala ${ }^{8}$, K. B. S. N. Jinadasa ${ }^{5}$ (D), \\ Sujithra K. Weragoda ${ }^{9}$ and Rohan Weerasooriya ${ }^{4}$
}

1 State Key Joint Laboratory of Environmental Simulation and Pollution Control, Research Center for Eco-Environmental Sciences, Chinese Academy of Sciences, Beijing 100085, China; indika_st@rcees.ac.cn (S.I.); dzhu_st@rcees.ac.cn (D.H.); tharindu_st@rcees.ac.cn (T.R.)

2 Laboratory of Water Pollution Control Technology, Research Center for Eco-Environmental Sciences, Chinese Academy of Sciences, Beijing 100085, China

3 University of Chinese Academy of Sciences, Beijing 100049, China

4 National Institute of Fundamental Studies, Hanthana Road, Kandy 20000, Sri Lanka; rohan.we@nifs.ac.lk

5 Department of Civil Engineering, University of Peradeniya, Peradeniya 20400, Sri Lanka; ketha94@eng.pdn.ac.lk (J.K.); shamj@pdn.ac.lk (K.B.S.N.J.)

6 Department of Applied Earth Sciences, Uva Wellassa University, Badulla 90000, Sri Lanka; titus@uwu.ac.lk

7 Post Graduate Institute of Science (PGIS), University of Peradeniya, Peradeniya 20400, Sri Lanka; 127charithahansima@gmail.com

check for updates

Citation: Indika, S.; Wei, Y.; Hu, D.; Ketharani, J.; Ritigala, T.; Cooray, T.; Hansima, M.A.C.K.; Makehelwala, M.; Jinadasa, K.B.S.N.; Weragoda, S.K.; et al. Evaluation of Performance of Existing RO Drinking Water Stations in the North Central Province, Sri Lanka. Membranes 2021, 11, 383. https://doi.org/10.3390/ membranes11060383

Academic Editors: Cezary

Artur Kozłowski and

Iwona Zawierucha

Received: 28 April 2021

Accepted: 19 May 2021

Published: 24 May 2021

Publisher's Note: MDPI stays neutral with regard to jurisdictional claims in published maps and institutional affiliations.

Copyright: (C) 2021 by the authors. Licensee MDPI, Basel, Switzerland. This article is an open access article distributed under the terms and conditions of the Creative Commons Attribution (CC BY) license (https:// creativecommons.org/licenses/by/ $4.0 /)$.
8 China-Sri Lanka Joint Research and Demonstration Center for Water Technology, Ministry of Water Supply, Meewathura, Peradeniya 20400,Sri Lanka; madhu10w@yahoo.com

9 National Water Supply and Drainage Board, Katugastota 20800, Sri Lanka; skwera7@gmail.com

* Correspondence: yswei@rcees.ac.cn; Tel.: +86-10-6284-9690

\begin{abstract}
Reverse osmosis (RO) drinking water stations have been introduced to provide safe drinking water for areas with prevailing chronic kidney disease with unknown (CKDu) etiology in the dry zone of Sri Lanka. In this investigation, RO drinking water stations established by communitybased organizations (CBO) in the North Central Province (NCP) were examined. Water samples were collected from source, permeate, and concentrate in each station to determine water quality and performance. Furthermore, the operators of the systems were interviewed to evaluate operational and maintenance practices to identify major issues related to the RO systems. Results show that the majority ( $>93 \%$ ) of $\mathrm{RO}$ systems had higher salt rejection rates $(>92 \%)$, while water recovery varied from $19.4 \%$ to $64 \%$. The removal efficiencies of hardness and alkalinity were averaged at 95.8\% and 86.6\%, respectively. Most dominant ions such as $\mathrm{Ca}^{2+}, \mathrm{Mg}^{2+}, \mathrm{K}^{+}, \mathrm{Na}^{+}, \mathrm{Ba}^{2+}, \mathrm{Sr}^{2+} \mathrm{Cl}^{-}, \mathrm{F}^{-}$, and $\mathrm{SO}_{4}{ }^{2-}$ showed higher rejections at averaged values of $93.5 \%, 97.4 \%, 86.6 \%, 90.8 \%, 95.4 \%, 96.3 \%$, $95.7 \%, 96.6 \%$, and $99.0 \%$, respectively. Low recovery rates, lower fluoride levels in product water, and membrane fouling were the main challenges. Lack of knowledge and training were the major issues that could shorten the lifespan of RO systems.
\end{abstract}

Keywords: reverse osmosis; performance; selectivity; salt rejection; permeate water recovery

\section{Introduction}

Safe and clean drinking water demand has been exponentially increasing around the globe due to the water quality degradation by environmental pollution as well as depletion of natural water bodies with the climate change. Even though Sri Lanka has not been an industrialized country, anthropogenic activities such as agricultural practices and waste disposal strategies have significantly influenced the quality of freshwater bodies in certain areas other than natural and environmental factors. In particular, rural communities in the dry zone of Sri Lanka, which cover two-thirds of the island, have suffered from severe health issues regarding the consumption of groundwater [1-4]. The prevalence of 
CKDu has been a life-threatening crisis for the farming community in the dry zone $[5,6]$. Until now, none studies have been conducted giving the exact cause for this disease. However, it has been emphasized that the drinking water quality issue might be the major cause of the origin of kidney disease [7,8]. Generally, the major drinking water source of the farming community in the dry zone had been raw groundwater for several decades. The conventional water treatment technologies used in Sri Lanka do not have the capability to remove excess dissolved minerals and possible nephrotoxins in the high hard groundwater in the dry zone. Therefore, advanced drinking water purification technologies such as RO membrane technology have been introduced and widely spread throughout the dry zone in the last decade to improve the drinking water quality $[9,10]$.

Generally, more than $2000 \mathrm{RO}$ drinking water stations have been established by different organizations [9,11], including government, non-government (NGOs), and some private companies throughout the north-central province (NCP). The CBOs, the Sri Lankan navy, the civil security department, and private companies mainly operate drinking water stations in the dry zone. The averaged treatment capacity of the systems ranges from 7.5 to $15 \mathrm{~m}^{3}$ per day. Moreover, different RO configurations, pre-treatment technologies, and posttreatment processes are available in this study area. Similarly, different operational and maintenance practices are followed by the operators in these $\mathrm{RO}$ stations. Previous studies have reported that many $\mathrm{RO}$ stations were not following proper or standard guidelines for operational practices. Thus, it has become a major problem that causes lower product water quality and reduced lifespan of the RO systems [9].

High removal rates of dissolved minerals and contaminants are the major advantage of the RO technology for drinking water production [12]. The production capability of soft drinking water from unpalatable high hard groundwater common in NCP has been significantly valuable. The existing RO stations in NCP have reported sufficiently high removal or rejection efficiencies (91-98\%) for major constituents such as TDS, hardness, alkalinity, silica, and major ions $\left(\mathrm{Ca}^{2+}, \mathrm{Mg}^{2+}, \mathrm{Na}^{+}, \mathrm{Cl}^{-}\right.$, and $\left.\mathrm{SO}_{4}{ }^{2-}\right)$ in the groundwater [10]. However, lack of essential minerals in the product $\mathrm{RO}$ water has been identified as a major drawback, leading to health issues related to nutrient deficiencies [13,14]. Most RO stations in NCP have been reported as having lower levels of essential minerals in the product water such as $\mathrm{Na}, \mathrm{K}, \mathrm{Ca}, \mathrm{Mg}$, and fluoride, which cause water palatability issues and mineral deficiency health issues such as dental decay [15-17]. Recently, other than inorganic constituents reported, the health effect from the dissolved organic fraction (DOC) in the groundwater has become a novel hypothesis for the CKDu issue in the dry zone [18]. Moreover, certain previous studies emphasized the unacceptable levels of DOC in the NCP region $[8,18,19]$, and an average of $55 \%$ of organic matter removal was observed in the RO systems in NCP [10]. Community feedback showed that the number of newly reported CKDu patients had been drastically reduced as an indication of improvement of community well-being by this drinking water treatment method. Therefore, to overcome the drawbacks such as higher removal of the essential minerals, previous studies have recommended advanced membrane technologies such as nano filtration (NF) and electro-dialysis reversal (EDR) water treatment strategies $[15,20]$.

$\mathrm{RO}$ membrane technology for drinking water purification has been very popular within the rural communities in the dry zone of Sri Lanka, especially after discovering $\mathrm{CKDu}$ disease. Although these $\mathrm{RO}$ systems in these regions are the major drinking water source that have already become widespread within last decade, thus far, no comprehensive study has been conducted to evaluate their performance, operational issues, and product water quality, except in a few general investigations based on a few RO stations $[9,10]$. Hence, the main objective of this study was to comprehensively evaluate the performance of CBO-established $\mathrm{RO}$ stations on the basis of their salt rejection capability and permeate water recovery. Identification of major operational and maintenance practices was the second objective. Furthermore, identification of product water quality issues, as well as estimation of production cost for RO drinking water in NCP, were carried out as final objectives. Thus, this study showed proper guidelines for future investigations regarding 
implementing and maintaining novel membrane technologies such as $\mathrm{RO}, \mathrm{NF}$, and EDR in Sri Lanka to supply clean and safe drinking water to the community.

\section{Materials and Methods}

\subsection{Study Area}

Anuradhapura and Polonnaruwa, which belong to the NCP in Sri Lanka, are the most affected regions by the CKDu health crisis. The quality of groundwater bodies in these regions is suspected to be the cause of this issue. Hence, NCP was selected as the study area, including all divisional secretariats (DSS) in Anuradhapura (22) and Polonnaruwa in this investigation. $\mathrm{CBO}$-operated $\mathrm{RO}$ stations are the most common $\mathrm{RO}$ drinking water stations in the rural community of the NCP. Therefore, CBO-operated medium- and small-scale RO drinking water stations installed in NCP were investigated, and 101 units of stations in NCP were selected by screening with the help of information given by NWSDB to represent all the CKDu prevailing regions in NCP. Out of them, 73 were from Anuradhapura, and the rest were from Polonnaruwa. Figure 1 shows locations of the investigated RO stations in NCP.

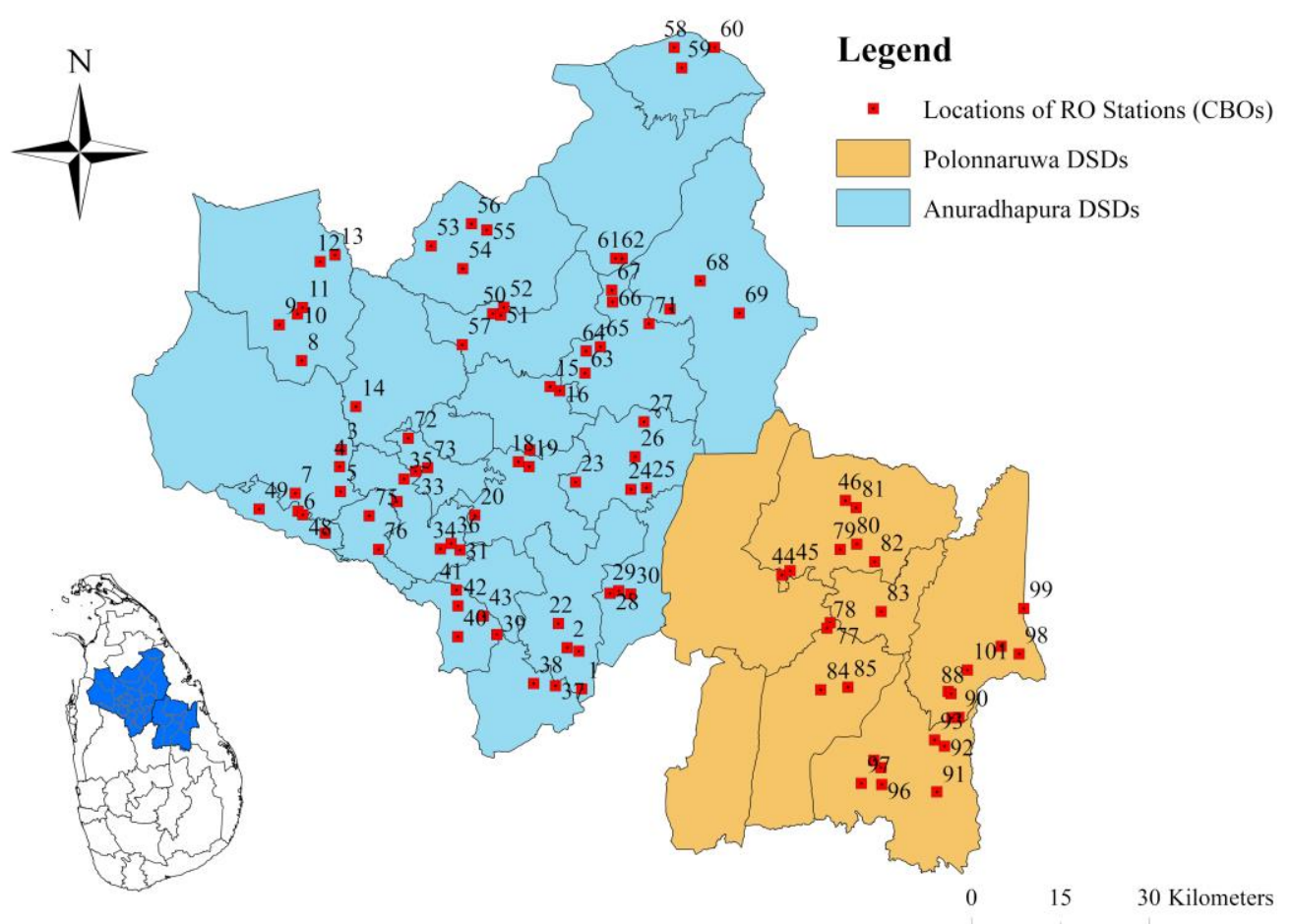

Figure 1. Locations of CBO-operated RO stations in North Central Province, Sri Lanka.

\subsection{Sampling and Data Collection}

A total of 101 units of RO systems (100 CBOs) were examined, and three major types of water samples (source, permeate, concentrate) were collected for water quality analysis to evaluate performance of each $\mathrm{RO}$ system. Collection of operational and maintenance practice information of each station was conducted by a questionnaire filled out by the operator who was responsible for the operation of the $\mathrm{RO}$ station. The operation conditions and system specification data were collected by direct observation. The questionnaire was focused on the RO system's basic information and treatment process, operational and maintenance practice, performance information, cost and income data, concentrate disposal, consumer feedback and comments, challenges, and recommendations. The consumer feedback survey was generally focused on their attitudes and opinions on RO drinking water quality, giving attention on whether it would be beneficial for their health to mitigate the CKDu issue in that area, whether it is consumable, would they have any problem with the taste or smell of RO drinking water, and what are the misconceptions about the 
RO drinking water. GPS locations and photographic information of all the RO systems were captured.

\subsection{Water Quality Analysis}

All the RO water samples were analyzed in the Environmental Laboratory, Faculty of Engineering, University of Peradeniya, Sri Lanka; National Water Supply and Drainage Board (NWSDB) Katugastota, Kandy; and NIFS laboratory Kandy for physical water quality parameters ( $\mathrm{pH}, \mathrm{EC}, \mathrm{TDS}$ ) and chemical parameters (hardness, alkalinity, metal cations, and anions). $\mathrm{pH}$ and EC of the water samples were analyzed by the Thermo Scientific Orion Star A325 Multiparameter meter. All the dominant and trace metals $\left(\mathrm{Ca}^{2+}, \mathrm{Mg}^{2+}, \mathrm{Na}^{+}, \mathrm{K}^{+}\right.$, $\mathrm{Li}^{+}, \mathrm{Sr}^{2+}, \mathrm{Ba}^{2+}, \mathrm{Mn}^{2+}, \mathrm{Fe}^{2+}, \mathrm{Cd}^{2+}, \mathrm{As}^{3+}, \mathrm{Cu}^{2+}, \mathrm{Zn}^{2+}, \mathrm{Cr}^{3+}, \mathrm{Hg}^{2+}$, and $\mathrm{Si}$ ) concentrations were measured by an inductively coupled plasma optical emission spectrophotometer (iCAP 7000 Series ICP-OES, Thermo Fisher Scientific, Waltham, MA, USA) in NIFS. The common anions $\left(\mathrm{Cl}^{-}, \mathrm{F}^{-}, \mathrm{Br}^{-}, \mathrm{SO}_{4}{ }^{2-}, \mathrm{NO}_{3}{ }^{-}\right.$, and $\left.\mathrm{PO}_{4}{ }^{3-}\right)$ were analyzed by an ion-chromatography instrument (Eco IC, Metrohm, Sweden) in the NWSDB. The total alkalinity was tested by the titrimetric method [21], and the total hardness was determined by the $\mathrm{Ca}^{2+}$ and $\mathrm{Mg}^{2+}$ concentrations in the water samples using the following equation:

$$
\text { Total hardness }\left(\mathrm{mg} / \mathrm{L} \mathrm{CaCO}_{3}\right)=2.497 \times[\mathrm{Ca}](\mathrm{mg} / \mathrm{L})+4.116 \times[\mathrm{Mg}](\mathrm{mg} / \mathrm{L})
$$

\subsection{Data Analysis}

Mineral (salt, hardness, alkalinity, cations, anions) rejections, permeate recovery, and ion permeability of $\mathrm{RO}$ membranes were used as the major performance criteria of the $\mathrm{RO}$ systems. Operational data collected by the questionnaires, manufacturer datasheets, and direct observation of the site were used to compare the actual operating conditions and standard conditions that are given by the manufacturers to identify the major issues with the operational and maintenance practices. Information related to the economy of the CBOs such as income, energy costs, replacement and chemical costs, and salaries were used to estimate the rough production cost for the RO drinking water. Origin Pro 2018 (64-bit) SR1 n9.5.1.195 (OriginLab Corporation, Northampton, MA, USA) and IBM SPSS Statistics for Windows, Version 26.0 (Armonk, NY, USA: IBM Corporation) software were used to analyze as a whole the water quality and other data in order to interpret it by the charts and diagrams. ArcGIS 10.3 for Desktop, Version 10.3.0.4322 (Esri Inc., Redlands, CA, USA) software was used to create maps related to this investigation. Equations for calculations of rejection and recovery are given below.

$$
\begin{gathered}
\% \text { Recovery }=(\text { permeate flow } / \text { feed flow }) \times 100 \% \\
\% \text { Rejection }=\left[\left(C_{f}-C_{p}\right) / C_{f}\right] \times 100 \%
\end{gathered}
$$

where

$\mathrm{C}_{\mathrm{f}}$ : influent concentration of a specific component, $\mathrm{mg} / \mathrm{L}$;

$\mathrm{C}_{\mathrm{p}}$ : permeate concentration of a specific component, $\mathrm{mg} / \mathrm{L}$.

\section{Results and Discussion}

\subsection{Comparison of RO Treatment Process}

There were different models of $\mathrm{RO}$ systems manufactured and distributed by different companies operating under different CBOs in the study area (Table S1). The basic filtration process was versatile in process configuration, pre-treatment methods, post-treatment methods, capacity, membrane type/manufacturer, reject-water handling, etc. Figure S1 shows the process flow diagram for a typical RO system in NCP. 


\subsubsection{Pre-Treatment Process}

The main pre-treatment units were used with sand/multimedia filtration, activated carbon (AC) filtration, water softening, and sediment filtration (MF or UF cartridges). The pre-treatment process plays a crucial role in order to avoid fouling and scaling on more expensive RO membranes due to silt or sediment [22]. The water softening unit was not available in the majority of RO systems. Only 36\% of RO stations (out of $101 \mathrm{RO}$ systems) contained a water softening unit. Sediment filters used in CBO-operated RO stations use two types of MF or UF cartridge, normally with 5-micron pore sizes. They are polypropylene (PP) poly spun melt blown and PP string-wound sediment filter cartridges.

A considerable number of $\mathrm{RO}$ systems $(>44 \%)$ use antiscalants to minimize $\mathrm{RO}$ membrane fouling and scaling. Two major antiscalant types with two different manufacturers were observed in the CBO-operated RO stations in NCP. The performance of these two regents was not evaluated. However, the dosage of antiscalant varied site by site. The antiscalant solution is usually injected into the pretreated (after sand, AC, and softener) water before the sediment cartridge filter (MF), which has been assembled before the high-pressure pump. The majority of operators use a solution with $50 \mathrm{~mL}$ of antiscalants dissolved in $100 \mathrm{~L}$ water for one week of production $(8400 \mathrm{~L})$.

Even though the antiscalant process is very common in RO stations in the NCP, it was observed that the majority of the operators do not have a clear idea about the purpose of the antiscalant. Due to this reason, some of the operators have stopped adding antiscalant because of the misunderstanding about the antiscalant as a chemical component that can be toxic for long-term human consumption. A significant number of consumers have a negative opinion about the chemicals added to drinking water in that they would lead to serious health effects. Thus, some of the RO stations have stopped adding minerals to RO filtered water in their re-mineralization process as well as in their antiscalant dosing process.

\subsubsection{RO Filtration}

All the RO stations in the study area use spiral wound membrane elements. The majority of them have the size of $4^{\prime \prime} \times 40^{\prime \prime} \mathrm{RO}$ elements. The number of RO skids and the configurations vary widely and depend on the capacity of the RO system. Figure S2 illustrates the most common configurations of $\mathrm{RO}$ systems in this region.

According to the number of stages, categorization of the RO systems can be done as shown in Table S2. We identified that the most common types of RO systems are single-stage with single RO element, two-stage serial arrangement with two RO elements, two-stage Christmas tree arrangement, and three-stage serial-type with three RO elements.

Apart from the configuration, different types or models of the $\mathrm{RO}$ membranes used in $\mathrm{CBO}$ of the NCP showed slightly different performances, even though they are made of the same polyamide material with TFC structure (Table S3). The most common RO membrane types used in RO systems in the NCP are manufactured by Hydranautics, VONTRON, and DOW filmtec. Usually, the pure aqua RO system uses Hydranautics (ESPA2-LD-4040) membranes inside their pressure vessels.

Usually, RO membranes used in the NCP are specified for different pressure ranges for different membrane models. On the basis of the tested operating pressure decided by the manufacturer to achieve $15 \%$ of permeate recovery per membrane element, we can categorize them into three main types of RO membranes: low pressure (LP), ultra-low pressure (ULP), and extremely low pressure (XLP) RO membranes.

\subsubsection{Post-Treatment Process}

Generally, ultraviolet (UV) radiation and remineralization units are used as the posttreatment processes for product permeate water. UV radiation has been widely used for the disinfection process for $\mathrm{RO}$ drinking water production while replacing the conventional chlorination process that can lead to the formation of carcinogenic disinfection by-products such as tri-halo-methane. Around 39.6\% of RO stations contained UV disinfection units and around $7.9 \%$ of ROs used a re-mineralization unit. The RO systems that produced 
permeate with very low TDS or EC level (TDS $<10 \mathrm{ppm}$ ) use the remineralization unit as a mineral adjustment method. Two major remineralization processes that are common in NCP are injecting pre-dissolved mineral solution into the permeate by an automatic dosing system and filtering RO permeate through the calcite bed/contactor. Two RO stations were observed as having calcite bed mineral addition.

\subsubsection{Reject Water Handling}

Production of wastewater (concentrate/reject water) from these $\mathrm{RO}$ stations was quite significant due to their lower recovery rates $(<50 \%)$. The majority of the CBOestablished RO stations did not have a proper wastewater disposal method. A total of $80 \%$ of RO stations simply reject their concentrated wastewater into open soil (Figure S3). However, only $10 \%$ of $\mathrm{RO}$ systems were found to consist of a reject water treatment unit such as multimedia filter. A few RO stations use their wastewater for gardening or cement construction purposes. However, some of the RO operators complained that RO wastewater is killing their cultivations. Therefore, they have stopped using wastewater for gardening purposes. Some villagers do not use the $\mathrm{RO}$ reject water as irrigation water for crops due to believing a myth that vegetables and fruits that are produced or cultivated by using wastewater from ROs become toxic and not suitable for human consumption. Hence, the feasibility of this $\mathrm{RO}$ reject water for irrigation purposes should be checked in future studies by analyzing different irrigation water quality measures.

\subsection{Operation and Maintenance}

CBO-operated $\mathrm{RO}$ stations do not have a standard operating guideline due to each RO system being donated/purchased and maintained by different organizations $[9,10]$. However, some organizations have provided detailed guidelines to some of the RO stations. Yet, it cannot be guaranteed that most of the $\mathrm{RO}$ operators are following the proper guideline for the operations of the RO systems. The NWSDB provides basic operational training for all the RO operators. Most of the CBO-operated RO stations have been under consultation and maintenance by NGOs other than NWSDB.

According to the information gathered during this study, the majority of the $\mathrm{RO}$ systems operated under CBOs have been installed after 2013. Thus, most of them are no more than eight years old (Figure S4). Hence, this technology is still new to the Sri Lankan water sector. Significantly lower daily operational time durations were observed from the RO stations in the NCP due to the lower demand for the drinking water from the CBO-operated RO systems. The average time of $4.4 \mathrm{~h}$ per day was observed, ranging from 1 to $24 \mathrm{~h}$ /day. The majority of the RO operators are farmers and do not have proper technical knowledge about operating and maintenance of the $\mathrm{RO}$ systems. Generally, $\mathrm{RO}$ operators do not involve extensive repairs in the RO system, such as replacing $\mathrm{RO}$ membrane modules, sand/activated carbon/resins in pre-filters, and pumps. Those tasks are usually performed by maintenance agents in the NWSDB or relevant authorities.

Operation and maintenance of these pre-treatment units are crucial for drinking water quality and the RO membrane life span, which directly influence the economy of the station. Around $72 \%$ of CBO-operated RO stations use daily backwashing routines (mostly automatic) before starting the filtration of the daily batch. They generally use raw groundwater to backwash the sand filter and AC filter. The softener unit is regenerated by injecting a normal salt $(\mathrm{NaCl})$ solution into the resin bed. In some other $\mathrm{RO}$ systems, the backwashing interval varies in between 2 days to 1 month. A few RO stations were reported as not following proper backwashing practices. Altitudes of the operators towards this service directly influence this kind of issue, which leads to a reduction overall RO system life span and weakening the economy of the CBOs. 
Normally, the sediment filter cartridge (MF, UF) in the pre-filter is replaced by the operator. The requirement of replacing that filter depends on the knowledge of the operator and training they have taken. In most cases, sediment cartridge replacement intervals were fixed. A total of $33.8 \%$ of CBO-established $\mathrm{RO}$ stations would replace their cartridge filters once every three months. This has been fixed by NWSDB or NGOs who consult with the CBOs. A few of the RO stations $(<5)$ have been recorded as never replacing the sediment cartridge/MF after installing the station. In the majority of RO systems under CBOs, this pre-filter was usually dissembled, washed, and cleaned using treated water once a week to reduce the replacement frequency and maintenance cost. A considerable number of $\mathrm{RO}$ operators (around $60 \%$ of $\mathrm{RO}$ stations) use color changes in the filtration membrane to indicate the replacement requirement. Usually, new filter cartridges (MF) are pure white, and after few days of operation, they become dark (brown or black) in color due to clogging sediments and inorganic precipitants such as oxides of iron and manganese in the feed groundwater. Frequent cleaning becomes ineffective after a few cleaning sessions, indicating the need for replacement of the filter cartridge. Generally, replacement intervals of sediment cartridges vary from 1 week to 6 months, depending upon the feed groundwater quality and the efficiency of the sand/activated carbon filters and softening unit.

Generally, RO membrane elements are replaced after a few years of operation due to the fouling and scaling, which leads to a reduction of water recovery. Replacement frequency is governed by maintenance and operational practices, the efficiency of the pretreatment system, and the feedwater quality. In the NCP, the majority of the $\mathrm{CBO}$-operated $\mathrm{RO}$ stations replace their membrane elements with a 2-3 year interval (Figure S5). Regular monitoring filtration performances are carried out by relevant consulting organizations and decide the required time to replace the membranes. Lower permeate recovery with the elevated system operating pressure due to the fouling or scaling is the indicator of the requirement of replacing the membrane elements. Normally, removed RO membranes are not regenerated to reuse. Therefore, new $\mathrm{RO}$ membrane elements have to be purchased by the CBOs, and the cost is covered by the income of the CBOs.

Operating pressure is one of the major and critical parameters that indicate the health of the $\mathrm{RO}$ membrane. Maintaining the proper and standard pressure inside the membrane is quite challenging because it is directly influenced by the chemistry of the feed water [12]. The changes in actual operating pressures inside the pressure vessels are significantly influenced by RO feed water quality, as well as fouling/scaling. In this study area, investigated RO systems were operated under an average 54-192 psi (372-1324 kPa) pressure range inside the RO vessels. Exceeded pressure indicates severe fouling or scaling with reduction of the water recovery. For the pressure in the recommended range to be maintained, the concentrate flow rate is adjusted by the operator, and it changes the production rate of permeate water. Lower pressure below the standard range is an indication of a damaged membrane element. The membrane can be damaged due to overpressure exerted due to the scaling or fouling and oxidation by the residual chlorine or other oxidizing compound remaining in the pre-treated water [12].

\subsection{Performance Analysis of RO Systems \\ 3.3.1. Water Quality}

The quality of RO feed/source water (groundwater) and product water (permeate) is summarized as in the following tables (Tables 1 and 2). 
Table 1. Feedwater (groundwater) quality of stations in NCP with the comparison of drinking water quality standards (WHO and SLS).

\begin{tabular}{|c|c|c|c|c|c|c|c|}
\hline Parameter & Units & Average & Max & Min & WHO MALs & SLS MALs & Unacceptable Samples (\%) \\
\hline \multicolumn{8}{|c|}{ Feedwater (groundwater) } \\
\hline \multicolumn{8}{|c|}{ General parameters } \\
\hline $\mathrm{pH}$ & & 7.1 & 8.3 & 6.95 & $6.5-8.5$ & $6.5-8.5$ & 0 \\
\hline EC & $\mu \mathrm{S} / \mathrm{cm}$ & 770 & 2430 & 112 & 400 & 750 & 98 \\
\hline Hardness & $\mathrm{mg} / \mathrm{L}\left(\mathrm{CaCO}_{3}\right)$ & 179.5 & 814 & 2.42 & - & 250 & 17 \\
\hline Alkalinity & $\mathrm{mg} / \mathrm{L}\left(\mathrm{CaCO}_{3}\right)$ & 320.4 & 1120 & 90 & - & 200 & 86 \\
\hline \multicolumn{8}{|c|}{ Anions } \\
\hline $\mathrm{F}^{-}$ & $\mathrm{mg} / \mathrm{L}$ & 1.16 & 4.9 & 0.03 & 1.5 & 1.0 & 21.8 \\
\hline $\mathrm{Cl}^{-}$ & $\mathrm{mg} / \mathrm{L}$ & 78.9 & 473.6 & 0.29 & - & 250 & 4 \\
\hline $\mathrm{Br}^{-}$ & $\mathrm{mg} / \mathrm{L}$ & 0.44 & 1.6 & 0.08 & 2 & - & 0 \\
\hline $\mathrm{NO}_{3}^{-}$ & $\mathrm{mg} / \mathrm{L}$ & 1.82 & 14.8 & 0.03 & 50 & 50 & 0 \\
\hline $\mathrm{PO}_{4}^{3-}$ & $\mathrm{mg} / \mathrm{L}$ & 4.08 & 6.3 & 0.93 & - & - & 0 \\
\hline $\mathrm{SO}_{4}^{2-}$ & $\mathrm{mg} / \mathrm{L}$ & 25.3 & 490.9 & 0.10 & 250 & 250 & 1 \\
\hline \multicolumn{8}{|c|}{ Cations } \\
\hline $\mathrm{Ca}^{2+}$ & $\mathrm{mg} / \mathrm{L}$ & 31.9 & 275.8 & 0.37 & - & 100 & 3.2 \\
\hline $\mathrm{Mg}^{2+}$ & $\mathrm{mg} / \mathrm{L}$ & 23.94 & 64.01 & 0.37 & - & 30 & 33.7 \\
\hline $\mathrm{Na}^{+}$ & $\mathrm{mg} / \mathrm{L}$ & 44.27 & 196.06 & 3.2 & 200 & 250 & 0 \\
\hline $\mathrm{K}^{+}$ & $\mathrm{mg} / \mathrm{L}$ & 2.85 & 88.21 & 0.14 & - & - & 0 \\
\hline $\mathrm{Li}^{+}$ & $\mu \mathrm{g} / \mathrm{L}$ & 7.47 & 26.65 & 0.354 & - & - & 0 \\
\hline $\mathrm{Sr}^{2+}$ & $\mu \mathrm{g} / \mathrm{L}$ & 606.92 & 2763.05 & 2.960 & - & - & 0 \\
\hline $\mathrm{Ba}^{2+}$ & $\mu \mathrm{g} / \mathrm{L}$ & 192.34 & 1698.17 & 0.340 & 1300 & - & 1 \\
\hline $\mathrm{Mn}^{2+}$ & $\mu \mathrm{g} / \mathrm{L}$ & 0.72 & 25.86 & 0.057 & 100 & 100 & 0 \\
\hline $\mathrm{Fe}^{2+}$ & $\mu \mathrm{g} / \mathrm{L}$ & 1.99 & 28.87 & 0.023 & 200 & 300 & 0 \\
\hline $\mathrm{Cd}^{2+}$ & $\mu \mathrm{g} / \mathrm{L}$ & 0.2 & 0.59 & 0.010 & 3 & 3 & 0 \\
\hline $\mathrm{As}^{3+}$ & $\mu \mathrm{g} / \mathrm{L}$ & 1.89 & 4.43 & 0.410 & 10 & 10 & 0 \\
\hline $\mathrm{Cu}^{2+}$ & $\mu \mathrm{g} / \mathrm{L}$ & 2.17 & 14.27 & 0.055 & 2000 & 1000 & 0 \\
\hline $\mathrm{Zn}^{2+}$ & $\mu \mathrm{g} / \mathrm{L}$ & 7.19 & 163.04 & 0.071 & 3000 & - & 0 \\
\hline $\mathrm{Cr}^{3+}$ & $\mu \mathrm{g} / \mathrm{L}$ & - & ND & ND & 50 & - & 0 \\
\hline $\mathrm{Hg}^{2+}$ & $\mu \mathrm{g} / \mathrm{L}$ & - & ND & ND & 6 & - & 0 \\
\hline $\mathrm{Si}$ & $\mathrm{mg} / \mathrm{L}$ & 45.03 & 95.95 & 3.690 & - & - & 0 \\
\hline
\end{tabular}

Table 2. Product water quality from RO stations in NCP with the comparison of drinking water quality standards (WHO and SLS).

\begin{tabular}{|c|c|c|c|c|c|c|c|}
\hline Parameter & Units & Average & Max & Min & WHO MALs & SLS MALs & Unacceptable Samples (\%) \\
\hline \multicolumn{8}{|c|}{ RO product (drinking) water } \\
\hline \multicolumn{8}{|c|}{ General parameters } \\
\hline $\mathrm{pH}$ & & 6.95 & 7.45 & 6.57 & $6.5-8.5$ & $6.5-8.5$ & 0 \\
\hline $\mathrm{EC}$ & $\mu S / \mathrm{cm}$ & 27.6 & 153 & 1.7 & 400 & 750 & 0 \\
\hline Hardness & $\mathrm{mg} / \mathrm{L}\left(\mathrm{CaCO}_{3}\right)$ & 7.2 & 141.5 & 0.37 & - & 250 & 0 \\
\hline Alkalinity & $\mathrm{mg} / \mathrm{L}\left(\mathrm{CaCO}_{3}\right)$ & 35 & 95 & 0 & - & 200 & 0 \\
\hline \multicolumn{8}{|c|}{ Anions } \\
\hline $\mathrm{F}^{-}$ & $\mathrm{mg} / \mathrm{L}$ & 0.07 & 0.9 & 0.02 & 1.5 & 1.0 & 0 \\
\hline $\mathrm{Cl}^{-}$ & $\mathrm{mg} / \mathrm{L}$ & 2.6 & 41.8 & 0.07 & - & 250 & 0 \\
\hline $\mathrm{Br}^{-}$ & $\mathrm{mg} / \mathrm{L}$ & 0.14 & 0.15 & 0.13 & 2 & - & 0 \\
\hline $\mathrm{NO}_{3}^{-}$ & $\mathrm{mg} / \mathrm{L}$ & 0.31 & 1.5 & 0.10 & 50 & 50 & 0 \\
\hline $\mathrm{PO}_{4}{ }^{3-}$ & $\mathrm{mg} / \mathrm{L}$ & 0.69 & 2.0 & 0.25 & - & - & - \\
\hline $\mathrm{SO}_{4}{ }^{2-}$ & $\mathrm{mg} / \mathrm{L}$ & 0.58 & 14.8 & 0.08 & 250 & 250 & 0 \\
\hline
\end{tabular}


Table 2. Cont.

\begin{tabular}{cccccccc}
\hline Parameter & Units & Average & Max & Min & WHO MALs & SLS MALs & Unacceptable Samples (\%) \\
\hline & & & & Cations & - & 100 & 0 \\
$\mathrm{Ca}^{2+}$ & $\mathrm{mg} / \mathrm{L}$ & 1.684 & 20.82 & 0.126 & - & 30 & 0 \\
$\mathrm{Mg}^{2+}$ & $\mathrm{mg} / \mathrm{L}$ & 0.741 & 24.53 & 0.013 & 250 & 0 \\
$\mathrm{Na}^{+}$ & $\mathrm{mg} / \mathrm{L}$ & 3.164 & 51.65 & 0.310 & 200 & - & - \\
$\mathrm{K}^{+}$ & $\mathrm{mg} / \mathrm{L}$ & 0.292 & 3.01 & 0.011 & - & - & - \\
$\mathrm{Li}^{+}$ & $\mu \mathrm{g} / \mathrm{L}$ & 2.773 & 14.29 & 0.090 & - & - & 0 \\
$\mathrm{Sr}^{2+}$ & $\mu \mathrm{g} / \mathrm{L}$ & 17.37 & 380.85 & 0.378 & - & - & 0 \\
$\mathrm{Ba}^{2+}$ & $\mu \mathrm{g} / \mathrm{L}$ & 5.989 & 109.47 & 0.306 & 1300 & - & 0 \\
$\mathrm{Mn}^{2+}$ & $\mu \mathrm{g} / \mathrm{L}$ & 0.198 & 5.63 & 0.012 & 100 & 100 & 0 \\
$\mathrm{Fe}^{2+}$ & $\mu \mathrm{g} / \mathrm{L}$ & 0.938 & 9.32 & 0.010 & 200 & 300 & 0 \\
$\mathrm{Cd}^{2+}$ & $\mu \mathrm{g} / \mathrm{L}$ & 0.033 & 0.34 & 0.002 & 3 & 3 & 0 \\
$\mathrm{As}^{3+}$ & $\mu \mathrm{g} / \mathrm{L}$ & 0.796 & 2.37 & 0.031 & 10 & 10 & 0 \\
$\mathrm{Cu}^{2+}$ & $\mu \mathrm{g} / \mathrm{L}$ & 1.035 & 12.44 & 0.009 & 2000 & - & 0 \\
$\mathrm{Zn}^{2+}$ & $\mu \mathrm{g} / \mathrm{L}$ & 4.453 & 107 & 0.011 & 3000 & - & 0 \\
$\mathrm{Cr}^{3+}$ & $\mu \mathrm{g} / \mathrm{L}$ & - & $\mathrm{ND}$ & $\mathrm{ND}$ & 50 & - & 0 \\
$\mathrm{Hg}^{2+}$ & $\mu \mathrm{g} / \mathrm{L}$ & - & $\mathrm{ND}$ & $\mathrm{ND}$ & 6 & - \\
$\mathrm{Si}$ & $\mathrm{mg} / \mathrm{L}$ & 2.333 & 20.28 & 0.157 & - & - \\
\hline
\end{tabular}

The majority of RO systems used groundwater as the primary feed water source. Slightly alkaline groundwater was observed in this region, in which $\mathrm{pH}$ value lied within the permissible range established by the WHO (6.5-8.5). A significant number of samples were observed as having elevated and unacceptable levels of EC (98\%), hardness (17\%), alkalinity $(86 \%)$, fluoride $(21.8 \%)$, and chloride $(4 \%)$ in this groundwater while exceeding their MALs given by WHO and SLS, as summarized in Table 1. All the dominant constituents in the groundwater have an origin of geogenic minerals (calcite and silicate minerals) rich in the lithosphere in the NCP area $[8,23,24]$. Agricultural communities have been consuming this hard groundwater for several decades before discovering the CKDu in the dry zone of Sri Lanka $[1,25]$. Therefore, the primary objectives of the implemented $\mathrm{RO}$ technology in this region were to remove the excess minerals to produce low mineralized, palatable, and toxin-free drinking water [10,15]. It was observed that $100 \%$ of samples were had water quality below the MALs established by relevant authorities (Table 2). The removal rates of dissolved constituents in the groundwater by this RO technology were significantly higher compared to the conventional methods. Some studies have emphasized that RO product water in these regions have unacceptably lower levels of essential minerals such as calcium, magnesium, and fluoride $[10,15]$. According to the results (Tables 1 and 2), the trace elements including $\mathrm{Mn}^{2+}, \mathrm{Fe}^{2+}, \mathrm{Cd}^{2+}, \mathrm{As}^{3+}, \mathrm{Cu}^{2+}$, $\mathrm{Zn}^{2+}, \mathrm{Cr}^{3+}$, and $\mathrm{Hg}^{2+}$ were observed within the acceptable levels in both groundwater and RO-treated water. In addition, the lack of fluoride in the permeate was one of the key findings. The groundwater in this study area $(21.8 \%)$ has an unacceptable level of fluoride levels ( $>1.5 \mathrm{mg} / \mathrm{L}$ ), which has led to severe health issues such as dental and skeletal fluorosis among the community in this area $[26,27]$. The fluoride removal efficiency (96.6\%) was significantly efficient by this treatment technology, but $95 \%$ of the RO drinking water samples were below the minimum permissible limit $(<0.5 \mathrm{mg} / \mathrm{L})$ by WHO and SLS standards. Therefore, most $\mathrm{RO}$ systems produced drinking water with higher quality that are safer and palatable for human consumption while mitigating the low essential minerals by adding minerals externally. However, previous studies have reported that vegetables and fruits that were cultivated in the dry zone region contain more minerals $\left(\mathrm{F}^{-}, \mathrm{Ca}^{2+}\right.$, and $\mathrm{Mg}^{2+}$ ) due to geological minerals in the soil and irrigation water [28]. It is obvious that the crops cultivated in these mineral-rich soils will add more essential minerals into the consumers' systems through their diet. Thus, lack of minerals in drinking water could not be a significant issue for communities in the study area. Previous studies recommended implementing advanced purification methods such as NF and EDR on the basis of the reported lower rejection rates of essential minerals $[20,29,30]$. The major drawback of these 
technologies are expensive and do not perform efficiently for brackish water treatment in Sri Lanka as much as expected [15]. Thus, few economically feasible solutions can be recommended by this study. Mixing RO permeates with pre-treated groundwater and surface water would be a simple solution rather than going for expansive and advanced treatment process implementations. Another solution is that the community should be well aware of this issue and encourage them to fulfil their nutrient need with other sources such as fruits and vegetables that are rich in minerals in the dry zone of Sri Lanka.

\subsubsection{Comparison of RO Performances}

$\mathrm{CBO}$-operated $\mathrm{RO}$ stations showed different performance levels and efficiencies due to deviations in feedwater quality, system configurations, pre-treatment processes, and operating and maintenance practices. Major performance indicators of RO systems such as permeate water recovery, salt rejection, individual ion rejections, membrane selectivity, and permeability for different constituents were evaluated in this study.

\section{Permeate Recovery}

Permeate water recovery was a major concern in the performance of membranebased water treatment stations. It affects the energy efficiency as well as the purification efficiency of the system. Thus, maintaining higher recovery rates reduces cost of operations. Exceeding the recommended recovery value can lead to serious membrane fouling and scaling, which could reduce the membrane lifetime. Having significantly lower recovery rates was one of the major issues within the RO systems in the NCP. Figures 2 and S6 show the detailed permeate recoveries in each drinking water station.

The average water recovery was around $38.7 \%$, and the majority of the RO stations (89\%) showed below $50 \%$ of water recovery. Further, the concentrate was more than $50 \%$ of the feed water. Generally, the recovery of the RO system is decided by the designer. It is a fixed value in the range from $50 \%$ to $85 \%$, and generally it is designed to achieve $75 \%$ water recovery [12]. Exceeding this range results in a high fouling and scaling rate due to lack of water flow in the concentrate side of the membrane, and reducing the permeate water quality and lowering the recovery results in higher production of wastewater, which leads to the lower energy efficiency of the system. As shown in Figures 2 and S6, it can be realized that a considerable amount of energy has been wasted by producing an unnecessary amount of wastewater. Most of the RO stations in this study area maintain their operating pressure at a fixed value, which was recommended by the consulting organizations, and it was usually adjusted by changing the concentrate flow by a manual valve. Gradual fouling and scaling on the membrane under fixed constant pressure operation leads to lowering of the permeate flow and increase in the concentrate flow due to reduction of the water permeability of the membrane. As a result, lower permeate recovery can be observed in older membranes. The effort to obtain higher recovery from these fouled membranes by lowering the concentrate flow could lead to an increase in the operating pressure at an unacceptable level. It can be led to damage to the membrane element and the high-pressure pump. Lower recovery and higher operating pressure are indications of $\mathrm{RO}$ membrane fouling and scaling. Hence, this indication was frequently used to decide the requirement for membrane replacements. 


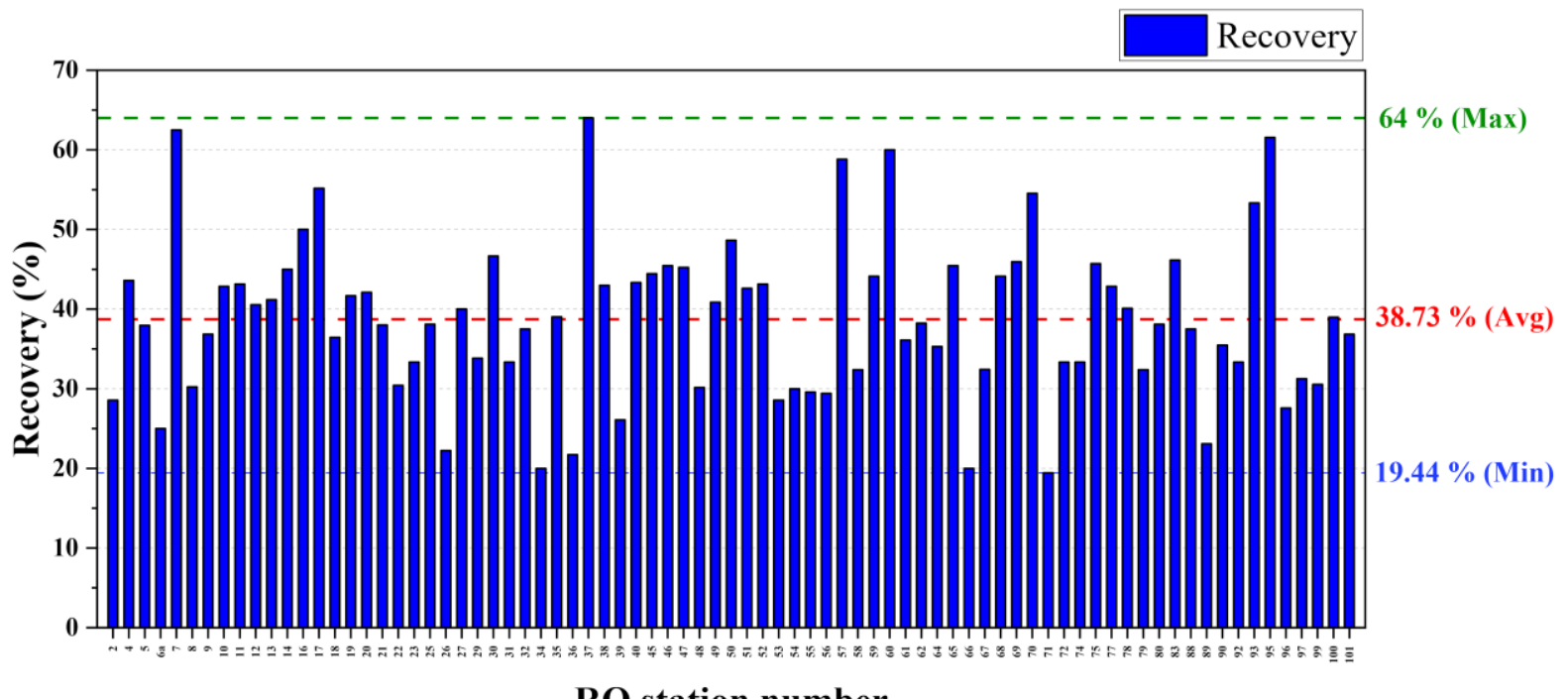

RO station number

Figure 2. Permeate recovery rates of each RO stations in NCP.

$\mathrm{RO}$ systems in the NCP consisted of small number of RO elements such as one $(22 \%)$, two $(44 \%)$, or three ( $26 \%$ ) elements per RO system (Table S2). Usually, a single RO membrane element can achieve only around $15 \%$ recovery under the standard operating pressures (Table S3). Thus, the maximum recovery it can achieve is $45 \%$ (15\% recovery per element $\times 3$ elements) for most RO systems. Therefore, having lower recoveries from these $\mathrm{RO}$ systems is obvious.

In this investigation, we identified and revealed that most RO systems are operated under much lower operating pressures while ignoring the recommendations of the manufacturer. Figure S7 illustrates the standard pressure values and actual operating pressures of selected RO systems. Usually, RO membranes used in the NCP can be categorized into three groups on the basis of their operational pressure ranges. They were low pressure (LP: $225 \mathrm{psi}$ or $1551 \mathrm{kPa}$ ), ultra-low pressure (ULP: $150 \mathrm{psi}$ or $1034 \mathrm{kPa}$ ), and extremely low pressure (XLP: $100 \mathrm{psi}$ or $690 \mathrm{kPa}$ ). According to the pressure and performance data, we found that lower recovery could occur due to lower operating pressures as well. Therefore, the operators should be well educated and trained for proper maintenance and standard operating conditions for the $\mathrm{RO}$ systems to achieve optimum productivity while increasing the durability and lifespan of the system.

\section{Hardness and Alkalinity Rejection}

Higher hardness level in the groundwater was common in this region- $-83 \%$ of the wells consisted of hard $\left(120-180 \mathrm{mg} / \mathrm{L} \mathrm{CaCO}_{3}\right)$ and very hard $\left(>180 \mathrm{mg} / \mathrm{L} \mathrm{CaCO}_{3}\right)$ groundwater in NCP. Unpalatable nature with unpleasant taste was the major issue with the higher hard waters $[8,31]$. In some studies, the total hardness of the drinking water was also examined for the CKDu cause [6,15,32]. Feedwater total hardness is an important factor to be addressed by this technology to produce drinking water. That was one of the major expectations when introducing the RO technology to the NCP last decade. This study observed relatively higher hardness removal rates in the existing RO systems in the NCP. The hardness rejection varied from $66.2 \%$ to $99.6 \%$ while having a significantly higher average of $95.8 \%$ (Figure $\mathrm{S} 8$ ). The results showed $\mathrm{RO}$ membranes have a higher capacity to demineralize hard water. Even though drinking water quality standards have not defined lower limits for essential minerals, some studies have suspected that long-term consumption of demineralized water leads to deficiencies in essential elements such as calcium and magnesium and causes serious health effects $[13,14]$. Re-mineralization of permeate can be achieved by filtering through a calcite bed/contactor $[33,34]$ or mixing with pre-treated sediment and pathogenic bacteria-free source water. 
Deviation of hardness rejection depends on the interaction of $\mathrm{Ca}^{2+}$ and $\mathrm{Mg}^{2+}$ ions with the $\mathrm{RO}$ membrane surface. The surface chemistry of the polyamide thin film composite (TFC) RO membranes and the feedwater quality control the rejection mechanism. Therefore, rejection of hardness can be explained by multivalent ion rejections by the RO membranes. Results showed that hardness rejection was significantly higher when feeding very hard groundwater to the RO systems (Figure 3b). The reason is the creation of ionic bonds between negatively charged polyamide TFC membrane surface (carboxyl and hydroxyl groups) and positively charged cations [35-37]. This phenomenon further enhances the rejection of multivalent ions but it encourages the fouling and scaling tendency on the membranes. Scaling by $\mathrm{CaSO}_{4}$ and $\mathrm{MgSO}_{4}$ can be accelerated due to the thickness of the stagnant water layer in the surface of the membrane, which is enhanced by the low water flowrate on the concentrate [12]. Hence, maintaining good recovery rates and concentrate flow upon the membrane is crucial to overcome the scaling by saturation of salts near the surface of the membranes. Similarly, RO systems with soft feedwater showed considerably lower hardness rejection for a significant number of RO systems (Figure 3b), which might have been due to the higher electrostatic attraction forces exerted by negatively charged membrane surface.
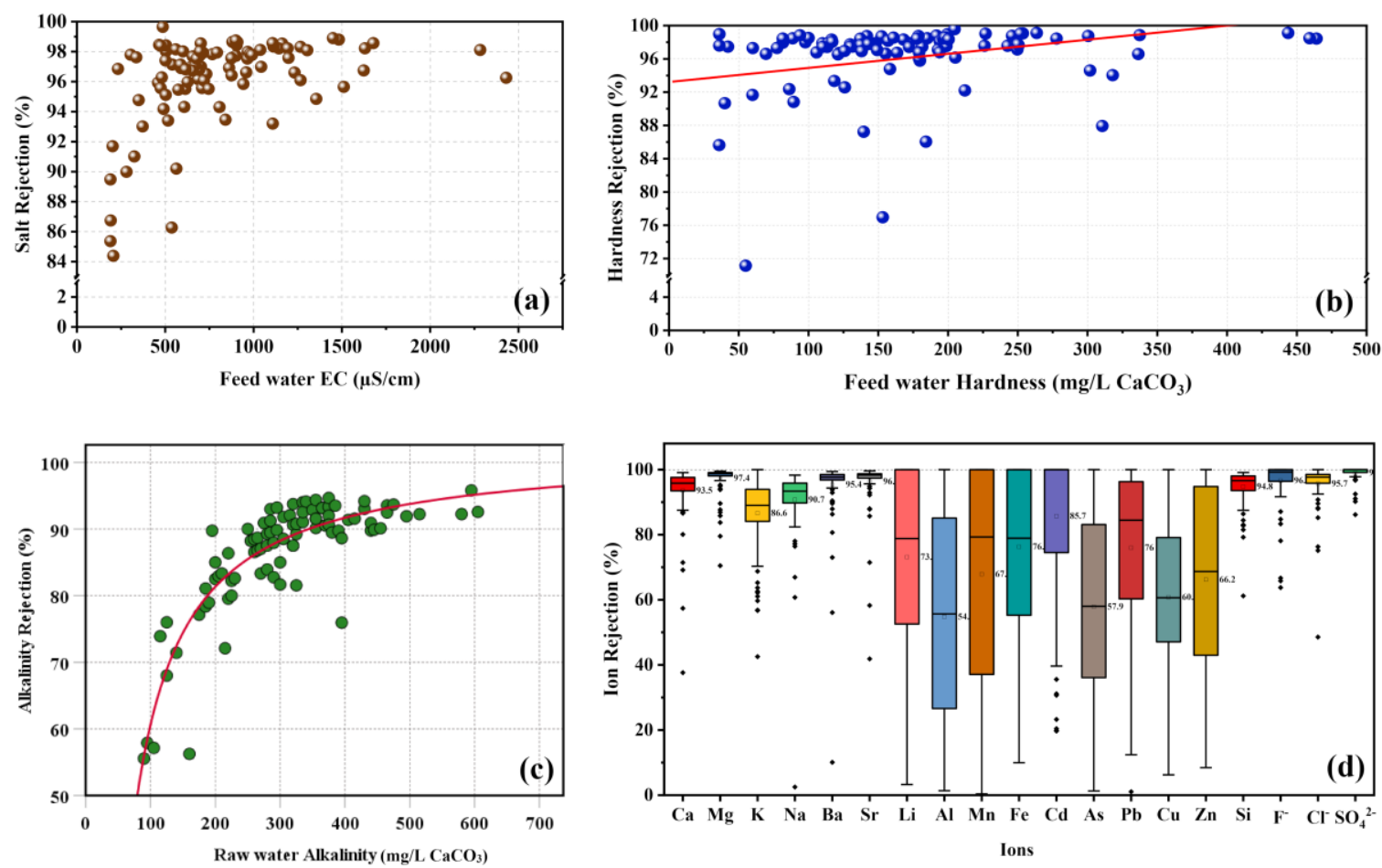

Figure 3. Performance of RO stations: (a) the salt rejection variation with the feed water EC; (b) hardness rejection efficiency with the feed water hardness; (c) alkalinity rejection rates with corresponding feed water alkalinity; (d) rejection of individual ions and silicon.

The alkalinity of groundwater is controlled by the dissolved inorganic carbon species $\left(\mathrm{HCO}_{3}{ }^{-}\right.$and $\left.\mathrm{CO}_{3}{ }^{2-}\right)$. Elevated levels of $\mathrm{HCO}_{3}{ }^{-}$-based alkalinity of groundwater in the $\mathrm{NCP}$ were generally indicated by their alkaline $\mathrm{pH}$ range (6.95-8.3). The rejection of alkalinity by RO systems varied from $55.6 \%$ to $96.9 \%$, while having an average of $86.6 \%$ (Figure S9). Alkalinity rejection showed a moderate correlation with the feedwater alkalinity $(r=+0.64, p<0.01)$. Further, the rejection rate showed an increasing trend with the feedwater alkalinity (Figure 3c). This would have been due to the additional removal of $\mathrm{HCO}_{3}{ }^{-}$ions that could occur at higher alkalinity by crystallization and precipitation near the membrane surface [38]. Usually, high alkaline groundwater consists of high hardness with $\mathrm{Ca}^{2+}$ and $\mathrm{Mg}^{2+}$ ions. The thicker concentration polarization (CP) layer occurs at high alkalinity and in very hard feed water, resulting in saturation limit reaching close to the 
membrane surface. Thus, crystallization of $\mathrm{CaCO}_{3}, \mathrm{CaSO}_{4}$, and $\mathrm{MgCO}_{3}$ can occur in the CP layer with high alkaline feed water. It further reduces the permeable $\mathrm{HCO}_{3}{ }^{-}$ion content at the membrane surface while maintaining a lower ion flux through the polyamide matrix. In consequence, high alkaline feedwater shows higher rejection rates. However, $\mathrm{CaCO}_{3}$ scaling potential becomes relatively higher at these conditions. Similarly, at lower alkalinity, groundwater has lower inorganic ions. Hence, resistance to entering the TFC layer and migrating to the permeate side is significantly lower, except in terms of the slight repulsive forces exerted by the negatively charged polyamide surface functional groups while giving lower alkalinity rejections [39].

\section{Salt Rejection}

The salt rejection efficiency of a $\mathrm{RO}$ system is a crucial factor in evaluating its performance. Typically, RO membranes have relatively higher salt rejection capability (>99\%) compared to other membrane filtration methods such as NF, UF, and microfiltration (MF) [12].

Salt rejection of $95 \mathrm{CBO}-$ established $\mathrm{RO}$ systems was evaluated, except in six RO systems that could not be covered for collection of source water samples due to technical issues. The average salt rejection was $95.9 \%$, in the range from $67.6 \%$ to $99.7 \%$. The majority of CBO-established RO systems (93\%) had salt rejection above $92 \%$ with excellent performance, except for seven RO systems (Figure S10).

According to the manufacturer, the minimum salt rejection would be above $99 \%$, but results showed less salt rejection. Reasons might be improper operation and maintenance practices, degradation of the membrane with age, and membrane fouling effect [9]. At lower operating pressure, $\mathrm{RO}$ membrane shows comparatively lower salt rejection while increasing the rejection with the increasing pressure [29]. Table S3 shows the standard pressure values and relevant salt rejection rates of each type of membrane model. Generally, RO membrane manufacturers measure the rejection rates of their membranes using a known concentration of $\mathrm{NaCl}$ solutions (1500 or $2000 \mathrm{ppm}$ ) under the standard pressure values in order to achieve $15 \%$ permeate recovery per one $\mathrm{RO}$ element (Hydranautics/Nitto, Oceanside, CA, USA).

Figure $3 \mathrm{~d}$ illustrates the individual ion rejections of the $\mathrm{RO}$ membranes used in drinking water stations in NCP. Most dominant metal cations in the groundwater, such as $\mathrm{Ca}^{2+}, \mathrm{Mg}^{2+}, \mathrm{K}^{+}, \mathrm{Na}^{+}, \mathrm{Ba}^{2+}, \mathrm{Sr}^{2+}$, and silicon (Si), were shown to have higher rejections at above $86 \%$. Other metal cations, including trace metals such as $\mathrm{Li}^{+}, \mathrm{Al}^{3+}, \mathrm{Mn}^{2+}, \mathrm{Fe}^{2+}, \mathrm{Cd}^{2+}$, $\mathrm{As}^{3+}, \mathrm{Cu}^{2+}$, and $\mathrm{Zn}^{2+}$, showed comparatively lower average rejection values and higher standard deviations. However, an acceptable level of trace metals in the product water was observed.

Most dominant anions in the groundwater were $\mathrm{Cl}^{-}$and $\mathrm{SO}_{4}{ }^{2-}$, while the availability varied in the order of $\mathrm{Cl}^{-}>\mathrm{SO}_{4}{ }^{2-}>\mathrm{NO}_{3}{ }^{-}>\mathrm{F}^{-}>\mathrm{Br}^{-}$. The rejection of dominant anions was analyzed to understand the performance of the filtering process by RO systems. The results showed that $\mathrm{RO}$ membranes had a higher capability of removing of dominant anions (>94\%) in the groundwater to produce safe drinking water with lesser inorganics.

\section{Factors of Ion Rejection}

Twenty-one units of RO systems (Pure Aqua, Santa Ana, CA, USA) with the same RO membrane ESPA2-LD-4040 manufactured by Hydranautics were analyzed for correlations with different operational factors such as feedwater EC, individual ion concentrations, operation pressure, and membrane age (Table 3 and Table S4). 
Table 3. Pearson correlation co-efficient of different operational parameters and individual ion rejections of ESPA2-LD-4040 membranes.

\begin{tabular}{cccc}
\hline Parameter & Membrane Age & Operating Pressure & Feed Water EC \\
\hline Salt rejection & $-0.681^{* *}$ & -0.026 & 0.182 \\
Ca rejection & -0.421 & -0.117 & 0.195 \\
Mg rejection & $-0.442^{*}$ & -0.049 & 0.008 \\
K rejection & $-0.550^{* *}$ & -0.414 & 0.410 \\
Li rejection & $-0.563^{*}$ & 0.360 & -0.058 \\
Na rejection & $-0.456^{*}$ & 0.060 & 0.264 \\
As rejection & 0.283 & -0.229 & -0.158 \\
Si rejection & -0.396 & 0.132 & 0.198 \\
\hline
\end{tabular}

** Correlation is significant at the 0.01 level (two-tailed); ${ }^{*}$ correlation is significant at the 0.05 level (two-tailed).

Membrane age is an important parameter that influences ion rejection. Usually, the membrane replacement interval varies from 6 months to 3 years in the NCP RO stations. Older membranes showed a significant reduction of rejection compared to newer membranes. The rejection of major cations in the feed water such as $\mathrm{Ca}^{2+}, \mathrm{Mg}^{2+}, \mathrm{K}^{+}, \mathrm{Li}^{+}$, and $\mathrm{Na}^{+}$showed low-to-moderate negative Pearson correlations $(-0.42,-0.442,-0.550$, -0.563 , and $-0.456: p<0.05$ ) with the membrane age, with an indication of the degradation of the membrane with the time (Table 3). $\mathrm{K}^{+}, \mathrm{Li}^{+}$, and $\mathrm{Na}^{+}$ions showed a significant relationship with the membrane age (Figure $4 \mathrm{a}, \mathrm{b}$ ). This may have been due to the lower hydration radius, higher mobility of the monovalent ions, and distorted degraded TFC layer [40]. Similarly, salt rejection also showed a significantly higher negative correlation $(\mathrm{r}=-0.68, p<0.01)$ with the membrane age and reduced rejection capability (Figure $4 \mathrm{c})$.
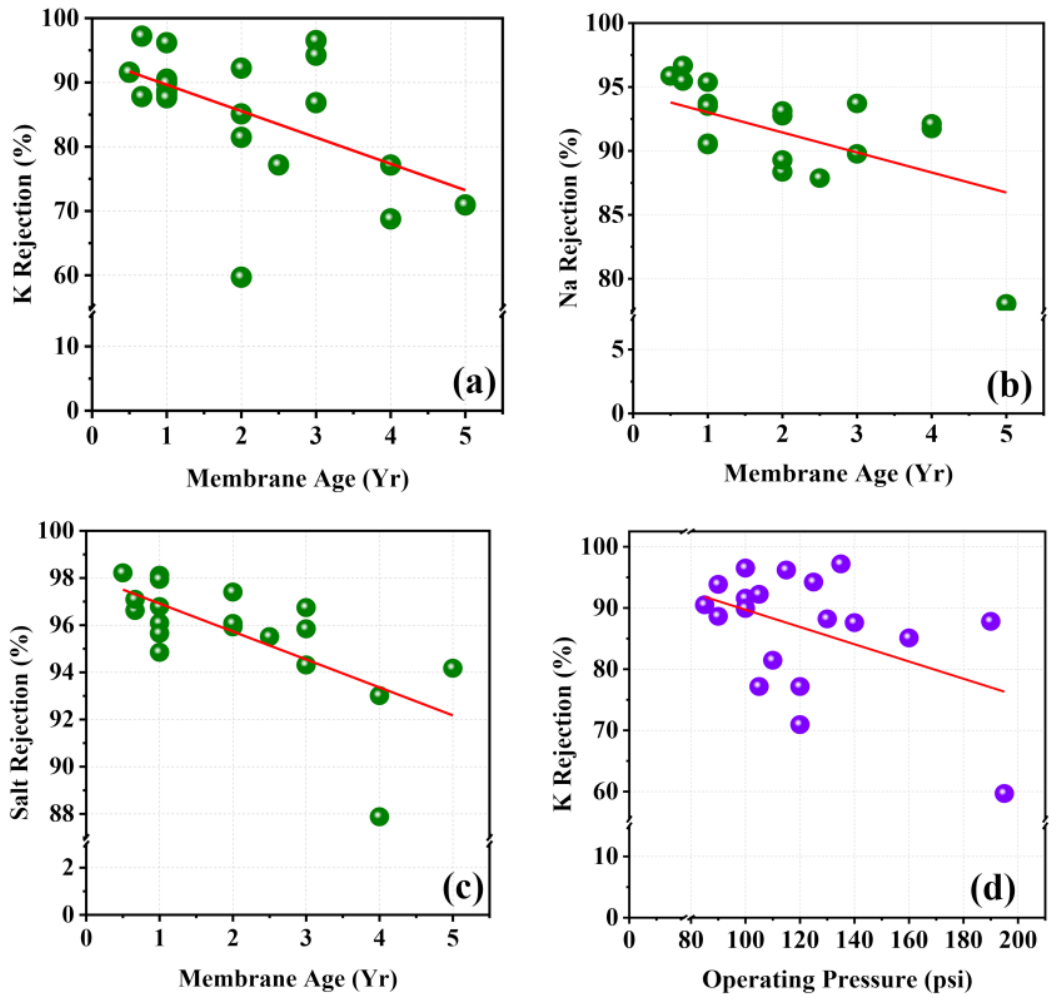

Figure 4. Rejections of monovalent ions with membrane age: (a) K rejection, (b) Na rejection, (c) salt rejection with membrane age, and (d) $\mathrm{K}$ rejection with operating pressure.

Monovalent ions such as $\mathrm{K}^{+}$showed a moderate negative correlation $(\mathrm{r}=-0.41$, $p=0.062$ ) with the operating pressure, while other ions showed a very weak negative correlation (Figure 4d). Smaller hydration radius and higher mobility of the monovalent ions gave comparatively lower resistance for intrapore diffusion through the polyamide 
matrix [39]. Similarly, slight expansion (swelling) of polymer (polyamide) matrix on the TFC layer at higher pressure could lead to increase in the porosity, allowing for permeation of more ions with smaller hydration radius, such as $\mathrm{K}^{+}$, through the membrane [41,42]. Such phenomena could be the major reason for having lower rejection of $\mathrm{K}^{+}$ions at higher operating pressure, as Figure $4 \mathrm{~d}$ shows.

All the RO membrane modules used in RO systems in NCP were polyamide TFC membranes. The most common products were DOW filmtec, Hydranautics, and VONTRON (Table S5). For the rejection of individual cations, these different RO elements showed different values for each cation. Figure 5 shows the number of RO stations that were used to determine the average rejection rates in this analysis.

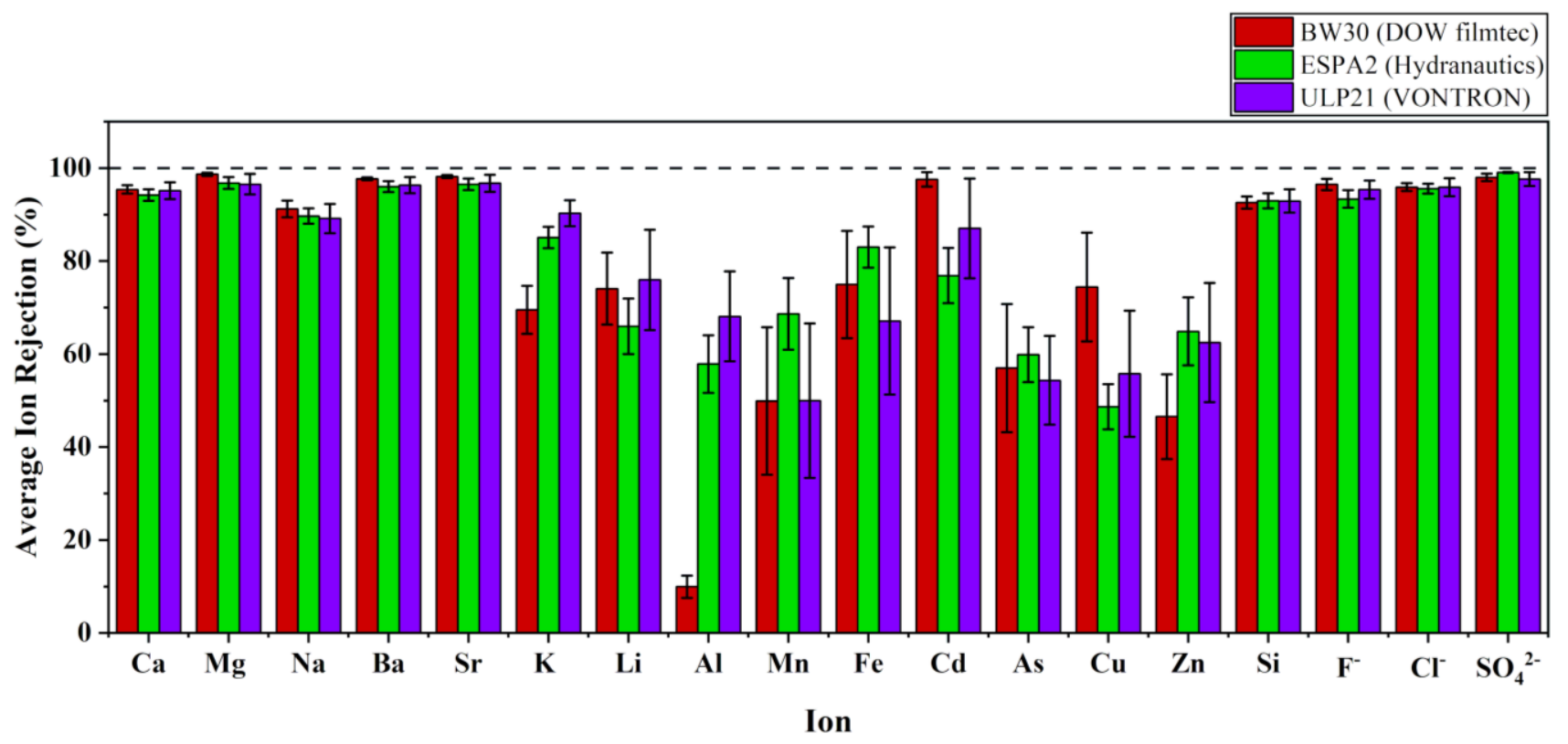

Figure 5. Average rejection of individual ions by three types of RO membranes.

Apart from the higher level of rejections ( $>89 \%)$, almost similar performances from all three types of membranes (BW30, ESPA2, and ULP21) were observed for dominant constituents $\left(\mathrm{Ca}^{2+}, \mathrm{Mg}^{2+}, \mathrm{Ba}^{2+}, \mathrm{Sr}^{2+}, \mathrm{Na}^{+}, \mathrm{Si}, \mathrm{F}^{-}, \mathrm{Cl}^{-}\right.$, and $\left.\mathrm{SO}_{4}{ }^{2-}\right)$. However, the rejection of monovalent cations $\left(\mathrm{Li}^{+}, \mathrm{K}^{+}\right)$and other trace metals $\left(\mathrm{Al}^{3+}, \mathrm{Mn}^{2+}, \mathrm{Fe}^{2+}, \mathrm{Cd}^{2+}, \mathrm{As}^{3+}, \mathrm{Cu}^{2+}\right.$, and $\mathrm{Zn}^{2+}$ ) showed different average values for each type of RO membrane. The lowest average rejection was observed for $\mathrm{Al}^{3+}$ ions by BW30 membrane, which was around $10 \%$ rejection. However, for $\mathrm{Fe}^{2+}, \mathrm{Cd}^{2+}$, and $\mathrm{Cu}^{2+}, \mathrm{BW} 30$ membrane showed comparatively higher rejection performances. Generally, for heavy metal removal, ESPA2 and ULP21 membranes showed sufficiently good performances.

\section{Variation of Performances with Different RO Configurations}

Figure 6 shows the comparison of performance in RO systems on the basis of their RO element configuration/arrangement. Multi-stage RO systems showed significantly higher water recovery compared to single-stage systems. However, double-stage RO systems with Christmas tree arrangement $(\mathrm{CT})$ recorded the optimum average recovery $(45.4 \pm 9.8 \%)$ value. Similarly, the salt rejection rate by the CT configuration also reported the highest value $(97.7 \pm 0.85 \%)$ among the different configurations while showing the best performance status, suggesting its suitability for sustainable water purification. Even though lower recovery values were reported with the $\mathrm{RO}$ systems with lower number of $\mathrm{RO}$ elements, salt rejection rates did not show a significant relationship with the number of stages or RO elements. 


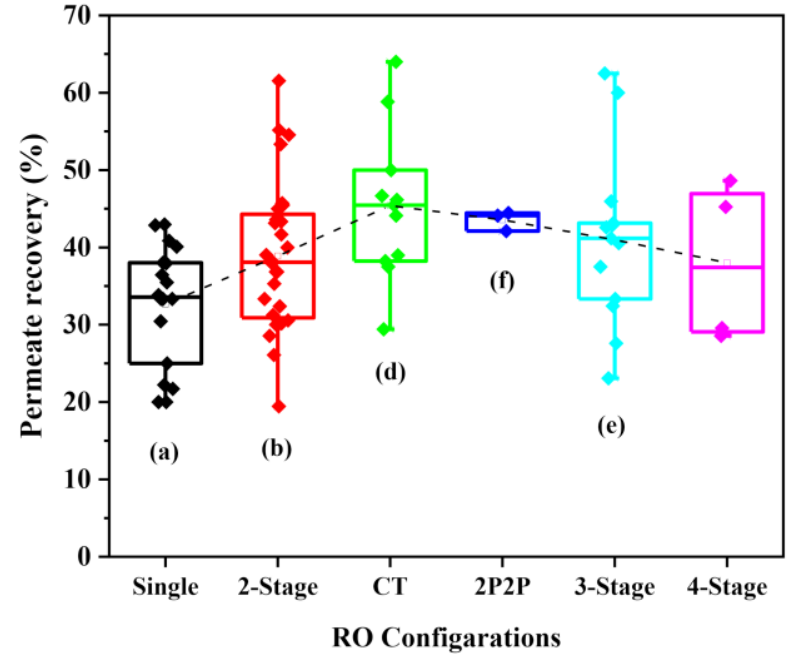
(a) Single - 1 element
(f) 2P2P - 4 elements (2 Parallel +2 Parallel)

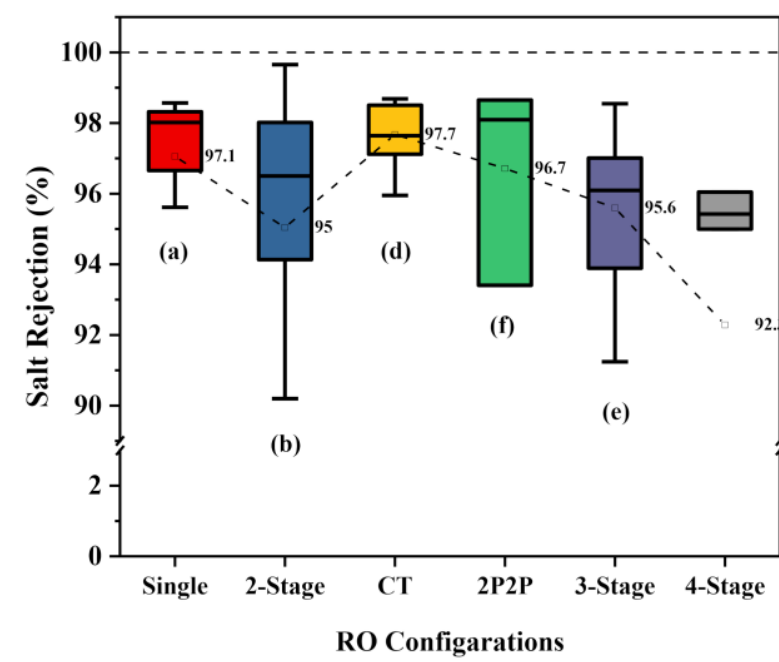

(b) 2-Stage - 2 elements (Serial)

(e) 3-Stage - 3 elements (Serial) (d) CT - 3 elements (Christmas Tree)

4-Stage - 4 elements (Serial)

Figure 6. Variation of permeate recovery (left) and the salt rejection rates (right) with the common RO configurations in NCP. Configurations indicated by $(\mathbf{a}, \mathbf{b})$ and $(\mathbf{d}-\mathbf{f})$ are illustrated in Figure S2.

Ion Selectivity and Permeability of Polyamide TFC RO Membranes

Ion selectivity and permeability of $\mathrm{RO}$ membranes are significantly important factors that affect the product water quality. The surface chemistry of the membrane and the feedwater quality are the major factors that control the ion selectivity and permeability. Thus, different relationships between ionic constituents in the feedwater and the permeate were compared to understand the mechanism behind the deviation of product water quality and the influence of membrane surfaces of RO systems.

\section{Selectivity and permeability of cations}

Figure 7 illustrates the relationship of major cations in permeate against the feedwater. Figure 7a shows that almost all the $\mathrm{Ca} / \mathrm{Mg}$ fractions of the permeate were positioned above the 1:1 line. Thus, the $\mathrm{Ca} / \mathrm{Mg}$ fraction was increased in the permeate compared to the feedwater, indicating the significantly higher permeability of $\mathrm{Ca}^{2+}$ ions in comparison with $\mathrm{Mg}^{2+}$ ions through the RO membrane. It confirmed the higher selectivity of $\mathrm{Ca}^{2+}$ ions for polyamide $\mathrm{RO}$ membranes.
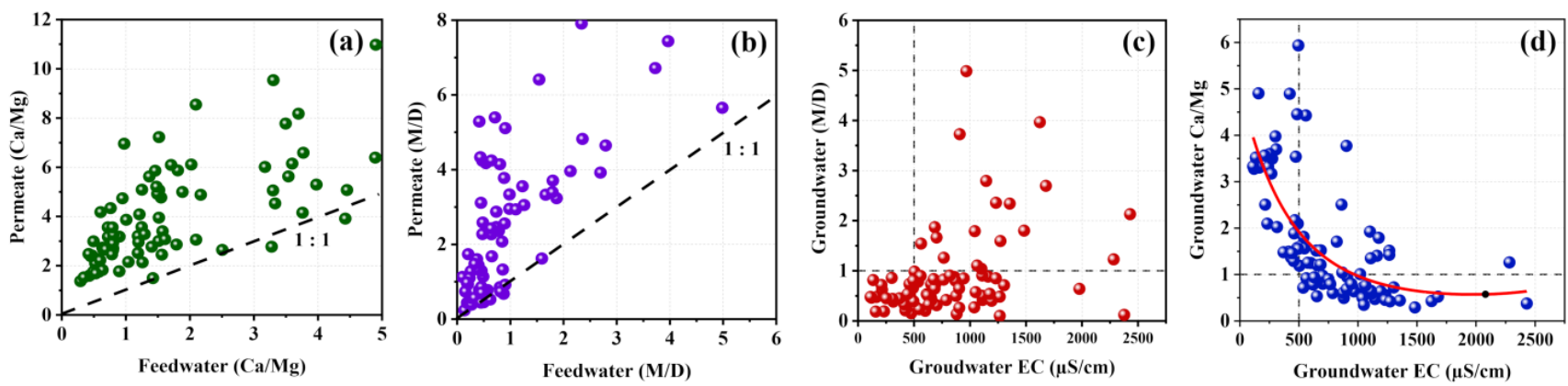

Figure 7. (a) Ca/Mg selectivity and permeability; (b) cation selectivity of monovalent/divalent (M/D) RO TFC membranes and (c) M/D ratio with groundwater EC; (d) $\mathrm{Ca} / \mathrm{Mg}$ ratio with groundwater EC in NCP.

Monovalent to divalent cation fraction (M/D) was increased after RO filtration (Figure $7 \mathrm{~b}$ ), revealing that permeate contains a higher monovalent cation percentage compared to the raw feed water. It indicates that the permeability of monovalent ions through polyamide $\mathrm{RO}$ membranes was higher than the divalent ions. The polyamide TFC layer 
allows for a considerable number of monovalent ions to pass through while providing significantly higher resistance to divalent hardness metals due to the lower hydration radius and higher mobility of monovalent ions [43].

As shown in Figure 7c, groundwater with a lower level of EC $(<500 \mu \mathrm{S} / \mathrm{cm})$ showed a significantly lower $\mathrm{M} / \mathrm{D}$ ratio $(<1)$, indicating the dominance of divalent ions in this region. However, high salinity groundwater seemed to have a significantly higher M/D ratio due to the presence of dominant monovalent cations in comparison with divalent cations. Similarly, at a lower level $(<500 \mu \mathrm{S} / \mathrm{cm})$ of salinity (EC), Ca/Mg ratio was comparatively higher $(>1)$, and groundwater with a higher level of salinity showed a lower $\mathrm{Ca} / \mathrm{Mg}$ ratio, which was an indication of $\mathrm{Ca}^{2+}$ dominancy in low salinity groundwater and $\mathrm{Mg}^{2+}$ dominancy in high salinity groundwater (Figure 7d).

$\mathrm{Ca}^{2+}$ ions, as the most dominant in groundwater, have significantly higher permeability through polyamide TFC membranes. When they are in lower concentrations, permeate $\mathrm{Ca}^{2+}$ ions tend to increase with the feedwater $\mathrm{Ca}^{2+}$ ion concentration (Figure 8b). This is because the electrostatic repulsion forces exerted by attached divalent ions $\left(\mathrm{Ca}^{2+}\right.$ and $\left.\mathrm{Mg}^{2+}\right)$ to the functional groups on the surfaces of the membrane is lower when feedwater contains dilute level of $\mathrm{Ca}^{2+}$ ions. The only resistance that affected the molecular transport of calcium is the energy barrier of the intrapore diffusion [39,44], resulting from the cations' interaction with the negatively charged internal pore walls. When the ion concentration becomes higher (especially $\mathrm{Ca}^{2+}$ ), more divalent ions attach to the membrane surface and cover a significant portion of the membrane surface [36] while providing enough repulsive force on the cations in solution. This restricts the entrance of calcium ions into the polyamide layer while resulting in a lower and stable calcium ion level in the permeate.

Even though $\mathrm{Mg}^{2+}$ ions have a higher level in feed, they have a comparatively higher hydration radius due to the higher charge density, which lowers the mobility and permeability in the solution [43,45]. Therefore, it reduces the capability of moving (permeability) through the polyamide matrix in the TFC layer, and permeate $\mathrm{Mg}^{2+}$ ion content keeps below $1 \mathrm{mg} / \mathrm{L}$ while following the linear relationship with the feed water $\mathrm{Mg}^{2+}$ ion level (Figure 8a). The interaction and binding energy of metal ions with the membrane surface group also controls the ion flux through the TFC layer. Usually, for carboxylic oxygen on polyamide membrane surfaces, divalent ions $\left(\mathrm{Ca}^{2+}\right.$ and $\left.\mathrm{Mg}^{2+}\right)$ have higher binding energy than monovalent ions, while the potential of bonding (attachments to the surface functional groups) order is maintained as $\mathrm{K}^{+}<\mathrm{Na}^{+}<\mathrm{Ca}^{2+}<\mathrm{Mg}^{2+}$ [46]. Therefore, a comparatively higher fraction of $\mathrm{Mg}^{2+}$ ions is strictly attached to the polyamide surface while a large portion of $\mathrm{Mg}^{2+}$ is ions rejected with the concentrate flow. Other cations that have lower levels in the feed water showed closely linear increasing trends with the feedwater ionic level, resulting in a lower level of these ions in the permeate (Figure 8c-f).

However, some monovalent ions such as sodium, present in higher concentrations in the feed, showed an increasing linear trend with the feed without being affected by the valance (Figure 8e). This may have been due to the higher permeability of monovalent ions in comparison with divalent ions. Monovalent ions have higher permeability through polymer membrane due to their lower hydration radius and higher mobility in aqua solution $[43,47]$. 

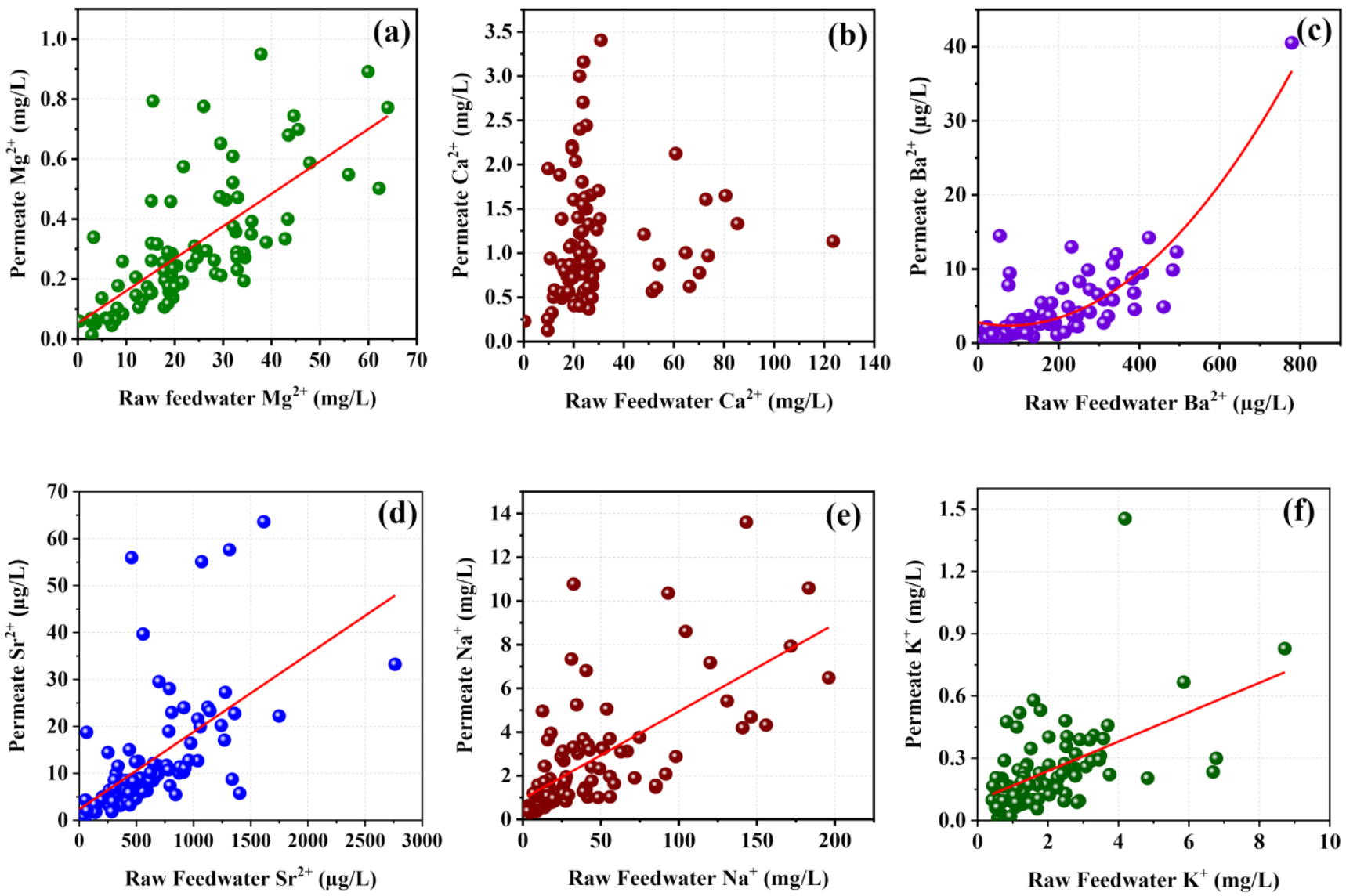

Figure 8. Major cation concentrations in the permeate with their feedwater cation concentrations, (a) variation of $\mathrm{Mg}^{2+}$ in the permeate with $\mathrm{Mg}^{2+}$ in the feedwater, (b) variation of $\mathrm{Ca}^{2+}$ in the permeate with $\mathrm{Ca}^{2+}$ in the feedwater, (c) variation of $\mathrm{Ba}^{2+}$ in the permeate with $\mathrm{Ba}^{2+}$ in the feedwater, (d) variation of $\mathrm{Sr}^{2+}$ in the permeate with $\mathrm{Sr}^{2+}$ in the feedwater, (e) variation of $\mathrm{Na}^{+}$in the permeate with $\mathrm{Na}^{+}$in the feedwater, and (f) variation of $\mathrm{K}^{+}$in the permeate with $\mathrm{K}^{+}$in the feedwater.

\section{Permeability of anions}

The surface of the polyamide TFC membranes used in RO systems in this study area was negatively charged due to the higher $\mathrm{pH}$ level of feed groundwater $[48,49]$. The electrostatic repulsion forces exerted by the surface charge on the anions were significantly higher. This phenomenon enhanced the rejection of anions, providing higher resistance to the partitioning of anions into the membrane matrix [39]. However, with the higher concentration of multivalent cations in the feedwater, major anions such as $\mathrm{Cl}^{-}$showed improved permeability through the RO membranes $(r=+0.727 . p<0.01)$ (Figure 9c). This occurred because of the most dominant divalent cations such as $\mathrm{Ca}^{2+}$ and $\mathrm{Mg}^{2+}$ ions in the feed, covering the negatively charged membrane surface by attaching to the surface functional groups while reducing the negativity of the surface, weakening the electrostatic repulsion forces on anions. Similarly, permeable $\mathrm{Cl}^{-}$ions showed strong positive correlation with the permeable monovalent cations, especially for $\mathrm{Na}^{+}(\mathrm{r}=+0.71 . p<0.01)$ (Figure 9a,b). This can be explained by interactions among monovalent cations, major anions, and pore walls of the membranes. Two major mechanisms can explain the anion diffusion through the polyamide membranes. The first one is anion transfer by pairing with the permeable cations to maintain the ion charge balance of the permeate $[39,44,47]$. The second mechanism is the separate permeation of anion due to the governing force of membrane potential exerted due to the fast permeation of monovalent cations with lower resistance to diffuse $[50,51]$. This membrane potential drags and speeds up the major anion $\left(\mathrm{Cl}^{-}\right)$movement through the TFC layer. 

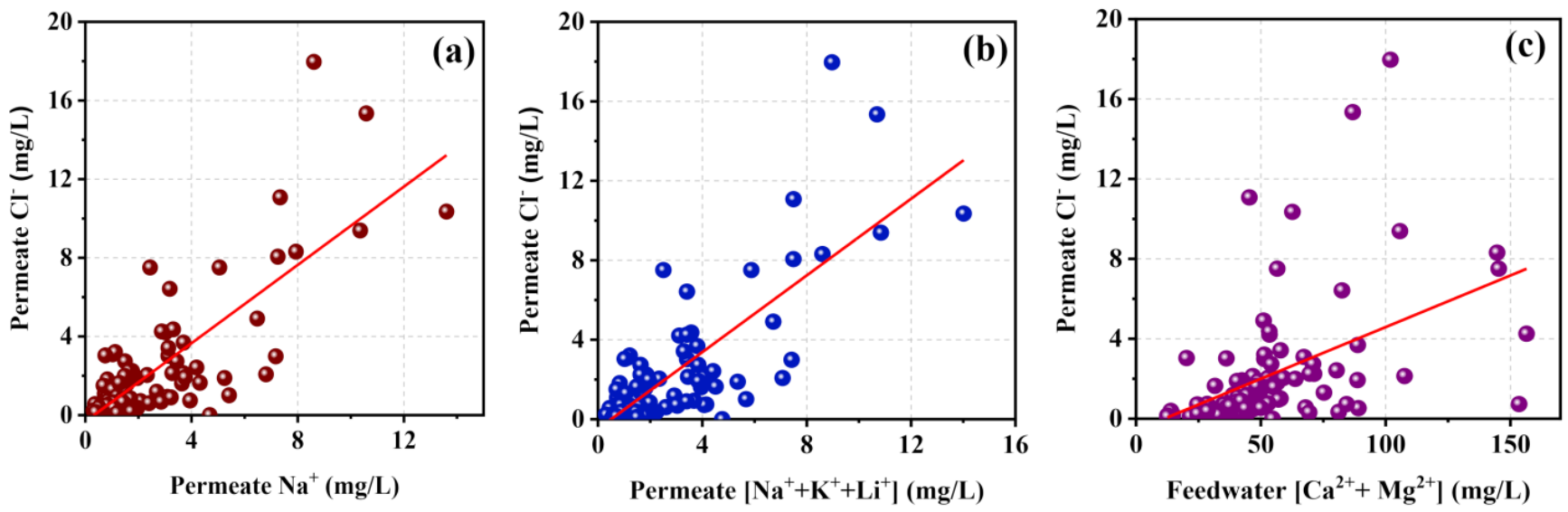

Figure 9. Chloride permeability through $\mathrm{RO}$ membranes with the concentration of (a) $\mathrm{Na}^{+}$in the permeate, (b) total monovalent cations in the permeate, and (c) divalent cations in the feedwater.

Silicon in the groundwater is usually neutral and stable $\left(\mathrm{Si}(\mathrm{OH})_{4}\right)$ at neutral and slightly acidic conditions. At higher alkalinity or higher $\mathrm{pH}$, some fraction is converted into $\mathrm{HSiO}_{4}{ }^{-}$, which has an ionic nature [52]. Consequently, the driving potential exerted by fast-moving cations (monovalent) and its pairing effect, $\mathrm{HSiO}_{4}{ }^{-}$transfer, was increased through the TFC layer, which was explained by the positive correlation between permeate monovalent cation level (especially $\left.\mathrm{Na}^{+}\right)$and silicon level $(\mathrm{r}=+0.531 . p<0.01)$.

As usual, the concentration of ions in the permeate was directly affected by the feed water ion concentration. Thus, dominant $\mathrm{Cl}^{-}$and $\mathrm{SO}_{4}{ }^{2-}$ ions showed moderate and strong positive correlations with their feed concentrations, respectively $(r=+0.685$ and +0.952 , $p<0.01$, respectively).

\subsection{Cost Analysis}

Table S1 shows the product water price ranges of RO stations operated by the relevant organization. The majority of the villagers belong to low- or middle-income populations. To develop health conditions and lifestyle, $\mathrm{CBOs}$ supply the $\mathrm{RO}$ drinking water at a reasonably low rate. Most of the CBO-operated $\mathrm{RO}$ stations ( $84 \%$ of $\mathrm{RO}$ stations) provide product drinking water at the standard price of LKR 1 (Sri Lankan rupee) per one liter. It ranges from 50 cents per liter to LKR 1.5 per liter. Usually, the average monthly income of the CBO-operated RO stations was around LKR 54,062.00, with the range from LKR 2250.00 to LKR 210,000.00 (Figure S11). Even though a few CBO-operated RO stations try to spread their services well, many RO stations were not well maintained. This depended on the attitude of the operators and $\mathrm{CBO}$ management, knowledge of the operators, and willingness to develop their service to the public community.

The average production cost of drinking water was estimated for a typical RO station in the NCP (Table S6), considering the cost for membrane replacements, antiscalants, replacements of pre-treatment materials (sand, AC, resin, sediment cartridges), pump repair, electricity, and salaries of the operators. Every material price was estimated according to the current rates in the Sri Lankan market. RO membrane elements, pre-filter materials, and sediment cartridge replacement intervals were assumed as two years, two years, and one month, respectively, on the basis of averaged values recorded in this investigation. The calculated average production cost of product water was around 49 cents per one liter (LKR $0.49 / \mathrm{L}$ ) in typical RO drinking water stations in the NCP that operated an average of $4.4 \mathrm{~h}$ /day. When it was assumed that the operational time was $20 \mathrm{~h}$ and working in full capacity $(10,000 \mathrm{~L} /$ day), we found that production costs were significantly lower at around 15 cents per liter $(0.145 \mathrm{LKR} / \mathrm{L})$. Therefore, the results indicated that working in full capacity can reduce the production cost of drinking water. 


\section{Challenges and Recommendations}

\subsection{Water Quality Issues}

Even though lower limits of water quality standards for total mineral content (EC or TDS) in the drinking water have not been clearly defined, consumption of demineralized water may lead to serious health issues. Similarly, insufficient fluoride levels $(<0.5 \mathrm{mg} / \mathrm{L})$ in the product water were also observed in this study due to the very high rejection capability of these $\mathrm{RO}$ membranes. Unnecessary levels of higher rejection rates for essential minerals are the major drawback of RO technology. Thus, increasing the level of essential minerals in $\mathrm{RO}$ product water remineralization is necessary. Major remineralization processes that $\mathrm{RO}$ stations used in the NCP are filtering through a calcite contactor and dosing a mineral solution to the product water. As mentioned in the previous sections, economically feasible simple methods such as mixing permeate with pretreated raw groundwater can be used to raise the mineral level in the product water. However, daily diet (fruits and vegetables) can fulfil the essential mineral need of the communities in the dry zone.

Even though the majority of villagers do not have proper knowledge about the EC value or TDS value, they have the uncertainty of whether RO drinking water has a low mineral level. This was one of the reasons for refusing to consume RO drinking water by some fraction of people in the study area. Therefore, frequent water quality monitoring should be carried out. In extreme and critical cases, alternative technologies such as NF and EDR, which have a higher selectivity for essential minerals to produce safer drinking water, should be checked for feasibility and implemented.

\subsection{CBO Organizational Issues}

$\mathrm{CBO}$-operated $\mathrm{RO}$ stations have great competition with other organizations such as the Sri Lankan Navy and private commercial organization-operated RO stations. This competition greatly affects the quality of the service they provide. Sri Lankan Navy-operated $\mathrm{RO}$ stations supply their RO drinking water free of charge. Consequently, villagers tend to take the water from them. Nearly 817 of navy-operated RO stations are already established throughout the country [11]. Normally, in the majority of villages in the NCP, at least one navy-operated $\mathrm{RO}$ station is available. Thus, demand for the CBO-operated $\mathrm{RO}$ water has declined. Consequently, the economy of the CBOs becomes weaker, and lower-income leads to difficulties in terms of handling the maintenance works. Thus, managing the salaries of operators as well as operational and maintenance costs is becoming a major issue for several $\mathrm{RO}$ stations under CBOs. Some of the $\mathrm{CBO}$-established $\mathrm{RO}$ stations have already been shut down permanently due to this economic issue.

Private company-operated $\mathrm{RO}$ stations are selling their water at significantly higher rates than the CBOs. However, they have home water delivery services. It is very convenient for the villagers, even though the price is higher. Therefore, especially in urban regions, this type of $\mathrm{RO}$ water service is more popular than $\mathrm{CBOs}$. To expand their service, CBO RO stations should be focused on starting delivery services and installing drinking water storage tanks in different parts of the villages for the convenience of the community. There are a few CBO RO stations already distributing drinking water using these kinds of water tanks. This helps to increase consumers and develop the economy of the CBOs as well as rural community well-being.

In some of the areas in the NCP, the majority of the community depends on pipeborne drinking water (purified tank water). Some of the areas with national reserves are rich in high-quality spring water. The majority of the villagers depend on spring water distribution by the government using bowsers. Hence, these types of RO stations are not common, and some $\mathrm{RO}$ stations have already been shut down due to the lack of consumers. Therefore, it is crucial that regular water quality monitoring and surveying of the water demand occurs in rural regions before advanced water purification technologies are installed. 
For the quality of the service to be improved, the CBO-established RO station network should be well organized, and continuous monitorization of product water quality should be carried out. To improve the altitudes toward this social service, RO system operators and other responsible persons should be well trained and educated by the relevant organizations. This would improve the operational and maintenance practices of the RO stations and drastically reduce the cost for the operation and maintenance, increasing the lifespan of the RO systems. Villagers should be well educated about the importance of consuming safe drinking water and how RO drinking water helps to improve their health.

\section{Conclusions}

Lack of essential minerals in the product drinking water, lower recovery rates, fouling and scaling, and lack of proper and standard guidelines for $\mathrm{RO}$ system operation have been identified as major issues with RO stations in the NCP.

Source water had elevated and unacceptable levels of EC (98\%), hardness (17\%), alkalinity ( $86 \%)$, fluoride $(21.8 \%)$, and chloride $(4 \%)$ while exceeding their MALs given by WHO and SLS drinking water guidelines. Treated RO drinking water was well below the MALs. However, $95 \%$ of samples had an unacceptable lower level of fluoride $(<0.5 \mathrm{mg} / \mathrm{L})$, leading to increased dental caries. Simple and economically friendly methods such as mixing permeate with pre-treated groundwater were suggested to raise essential minerals (fluoride, calcium, and magnesium), and daily diet was suggested in order to fulfil the nutrient need of the consumers.

Having insufficient numbers of RO elements in each system in the NCP, operation under lower pressure, and membrane fouling were the major causes for lower permeate recoveries (average, 39\%), which ranged from 19.4\% to 64\%. The majority (>93\%) of RO systems showed higher salt rejection rates (>92\%). Excellent removal rates of hardness and alkalinity were averaged at $95.8 \%$ and $86.6 \%$, respectively. However, Christmas tree RO configuration was identified as the best option for sustainable water purification, which showed optimum recovery and salt rejection rates. Most dominant ions in groundwater such as $\mathrm{Ca}^{2+}, \mathrm{Mg}^{2+}, \mathrm{K}^{+}, \mathrm{Na}^{+}, \mathrm{Ba}^{2+}, \mathrm{Sr}^{2+} \mathrm{Cl}^{-}, \mathrm{F}^{-}, \mathrm{SO}_{4}{ }^{2-}$, and silicon (Si) were shown at higher rejections and were averaged at 93.5\%, 97.4\%, 86.6\%, 90.8\%, 95.4\%, 96.3\%, 95.7\%, $96.6 \%, 99.0 \%$, and $94.8 \%$, respectively. The trace elements such as $\mathrm{Mn}^{2+}, \mathrm{Fe}^{2+}, \mathrm{Cd}^{2+}$, $\mathrm{As}^{3+}, \mathrm{Cu}^{2+}$, and $\mathrm{Zn}^{2+}$ showed significantly lower rejections. Rejection of monovalent ions $\left(\mathrm{Na}^{+}, \mathrm{K}^{+}\right)$showed a decreasing trend with the membrane age and operating pressure due to degradation of polyamide matrix of the TFC layer and membrane swelling at higher pressures.

The permeability of monovalent ions was significantly higher than divalent ions through polyamide $\mathrm{RO}$ membranes, while significantly higher $\mathrm{Ca}^{2+} / \mathrm{Mg}^{2+}$ selectivity was observed. Permeability of $\mathrm{Cl}^{-}$ion was improved with the concentrations of multivalent ions $\left(\mathrm{Ca}^{2+}\right.$ and $\left.\mathrm{Mg}^{2+}\right)$ in the feedwater and permeable monovalent cations $\left(\mathrm{Na}^{+}\right)$.

Most dominant constituents ( $\mathrm{Ca}, \mathrm{Mg}, \mathrm{Sr}, \mathrm{Ba}, \mathrm{Na}, \mathrm{Si}, \mathrm{F}, \mathrm{Cl}$, and $\mathrm{SO}_{4}{ }^{2-}$ ) present in the source water showed a higher and similar level of removal efficiencies $(>89 \%)$ for all three types of membranes (BW30, ULP21, and ESPA2).

The estimated production cost of RO drinking water was 49 cents (LKR 0.49/L) for a $\mathrm{CBO}$-operated $\mathrm{RO}$ station with an average operational duration of $4.4 \mathrm{~h}$. However, full-timeoperated (20 h/day) RO stations showed 15 cents (LKR 0.145/L) of production cost while indicating that lower operational duration increases $\mathrm{RO}$ drinking water production cost.

Lack of knowledge and lack of proper guidelines for operation and maintenance practices leads to degradation of performance of ROs. Thus, CBOs may require further assistance from the water supply authorities regarding chemical cleaning of the RO systems, water quality testing, and technical training for operators. 
Supplementary Materials: The following are available online at https:/ / www.mdpi.com/article/10 $.3390 /$ membranes11060383/s1, Figure S1. Process flow diagram of a typical RO system in the NCP. Figure S2. Different RO configurations that are common in NCP, Sri Lanka. Figure S3. Different options for reject water handling. Figure S4. Number of RO systems with their system age (Y). Figure S5. Percentage of the number of CBO-operated RO facilities ( $x$-axis) in the NCP with their membrane replacement intervals ( $x$-axis). Figure S6. Number of RO plants ( $y$-axis) with the categorization by their water recovery as a percentage ( $x$-axis). Figure S7. Tested (by manufacturer) operating pressure vs. actual operating pressure of selected RO systems in the NCP. Figure S8. Hardness rejection of each RO station. Figure S9. Alkalinity rejection rates of each RO station. Figure S10. Overall salt rejection for each RO plant (95 ROs) operated under CBOs ( $x$-axis: RO plant number, $y$-axis: \% salt rejection). Figure S11. Total income and total operating cost of each RO station in the NCP. Table S1. RO product water prices with their operating companies. Table S2. Diversity of RO system configurations in CBOs in the NCP. Table S3. Specification data of each RO membrane type used in RO stations in the NCP. Table S4. Influence of feedwater chemistry for ion rejection of ESPA2 membranes. Table S5. Selected RO membranes for comparison of individual ion rejection. Table S6. Estimation of production cost for drinking water in a typical RO station in NCP.

Author Contributions: Conceptualization, S.I. and Y.W.; methodology, S.I. and Y.W; software, S.I.; validation, S.I., Y.W., and T.R.; formal analysis, S.I., M.A.C.K.H., and J.K.; investigation, S.I., J.K., D.H., and M.M.; resources, Y.W., K.B.S.N.J., S.K.W., and R.W.; writing—original draft preparation, S.I.; writing-review and editing, Y.W., T.R., and T.C.; supervision, Y.W.; funding acquisition, Y.W. All authors have read and agreed to the published version of the manuscript.

Funding: This research was funded by the Joint Research Program of National Natural Science Foundation of China and National Science Foundation of Sri Lanka (NSFC-NSF SL) (21861142020); the Alliance of International Science Organizations Collaborative Research Program (ANSO-CR-KP2020-05); the Belt and Road Master Fellowship Program (fellowship no. 2018BRF040); the Program of China-Sri Lanka Joint Center for Water Technology Research and Demonstration by the Chinese Academy of Sciences (CAS); and the China-Sri Lanka Joint Center for Education and Research by the CAS.

Institutional Review Board Statement: Not applicable.

Informed Consent Statement: Not applicable.

Data Availability Statement: The data presented in this study are available on request from the corresponding author.

Conflicts of Interest: The authors declare no conflict of interest.

\section{References}

1. Dharma-Wardana, M.W.C.; Amarasiri, S.L.; Dharmawardene, N.; Panabokke, C.R. Chronic kidney disease of unknown aetiology and ground-water ionicity: Study based on Sri Lanka. Environ. Geochem. Health 2015, 37, 221-231. [CrossRef] [PubMed]

2. Wimalawansa, S.A.; Wimalawansa, S.J. Impact of changing agricultural practices on human health: Chronic kidney disease of multi-factorial origin in Sri Lanka. Wudpecker J. Agric. Res. 2014, 3, 110-124.

3. Wimalawansa, S.J. The role of ions, heavy metals, fluoride, and agrochemicals: Critical evaluation of potential aetiological factors of chronic kidney disease of multifactorial origin (CKDmfo/CKDu) and recommendations for its eradication. Environ. Geochem. Health 2016, 38, 639-678. [CrossRef] [PubMed]

4. $\quad$ Perera, W.P.R.T.; Dayananda, M.D.N.R.; Liyanage, J.A. Exploring the root cause for chronic kidney disease of unknown etiology (CKDU) via analysis of metal ion and counterion contaminants in drinking water: A study in Sri Lanka. J. Chem. 2020, 2020. [CrossRef]

5. Pinto, U.; Thoradeniya, B.; Maheshwari, B. Water quality and chronic kidney disease of unknown aetiology (CKDu) in the dry zone region of Sri Lanka: Impacts on well-being of village communities and the way forward. Environ. Sci. Pollut. Res. 2020, 27, 3892-3907. [CrossRef] [PubMed]

6. Balasooriya, S.; Munasinghe, H.; Herath, A.T.; Diyabalanage, S.; Ileperuma, O.A.; Manthrithilake, H.; Daniel, C.; Amann, K.; Zwiener, C.; Barth, J.A.C.; et al. Possible links between groundwater geochemistry and chronic kidney disease of unknown etiology (CKDu): An investigation from the Ginnoruwa region in Sri Lanka. Expo. Heal. 2019. [CrossRef]

7. Wanasinghe, W.C.S.; Gunarathna, M.H.J.P.; Herath, H.M.P.I.K.; Jayasinghe, G.Y. Drinking Water Quality on Chronic Kidney Disease of Unknown Aetiology (CKDu) in Ulagalla Cascade, Sri Lanka. Sabaragamuwa Univ. J. 2018, 16, 17-27. [CrossRef]

8. Cooray, T.; Wei, Y.; Zhong, H.; Zheng, L.; Weragoda, S.; Weerasooriya, R. Assessment of Groundwater Quality in CKDu Affected Areas of Sri Lanka: Implications for Drinking Water Treatment. Int. J. Environ. Res. Public Health 2019, 16, 1698. [CrossRef] 
9. Jayasumana, C.; Ranasinghe, O.; Ranasinghe, S.; Siriwardhana, I.; Gunatilake, S.; Siribaddana, S. Reverse osmosis plant maintenance and efficacy in chronic kidney disease endemic region in Sri Lanka. Environ. Health Prev. Med. 2016, 21, 591-596. [CrossRef]

10. Imbulana, S.; Oguma, K.; Takizawa, S. Evaluation of groundwater quality and reverse osmosis water treatment plants in the endemic areas of Chronic Kidney Disease of Unknown Etiology (CKDu) in Sri Lanka. Sci. Total Environ. 2020, 745, 140716. [CrossRef]

11. Sri Lanka Navy Navy Built RO Plants in Ampara Vested with the Public. Available online: https://news.navy.lk/eventnews/20 21/02/06/202102061300/ (accessed on 22 April 2021).

12. Baker, R.W. Membrane Technology and Applications, 3rd ed.; John Wiley \& Sons: Hoboken, NJ, USA, $2012 ;$ ISBN 1118359690.

13. Verma, K.C.; Kushwaha, A.S. Demineralization of drinking water: Is it prudent? Med. J. Armed Forces India 2014, 70, 377-379. [CrossRef]

14. Kozisek, F. Health Risk from Drinking Demineralized Water. Roll. Revis. WHO Guidel. Drink. Water Qual. 2004, 1, $148-163$.

15. Cooray, T.; Wei, Y.; Zhang, J.; Zheng, L.; Zhong, H.; Weragoda, S.K.; Weerasooriya, R. Drinking-Water supply for CKDu affected areas of Sri Lanka, using nanofiltration membrane technology: From laboratory to practice. Water 2019, 11, 2512. [CrossRef]

16. Balasubramanya, S.; Stifel, D.; Horbulyk, T.; Kafle, K. Chronic kidney disease and household behaviors in Sri Lanka: Historical choices of drinking water and agrochemical use. Econ. Hum. Biol. 2020, 37, 100862. [CrossRef]

17. Horbulyk, T.; Kafle, K.; Balasubramanya, S. Community response to the provision of alternative water supplies: A focus on chronic kidney disease of unknown aetiology (CKDu) in rural Sri Lanka. Water Int. 2021, 46, 37-58. [CrossRef]

18. Makehelwala, M.; Wei, Y.; Weragoda, S.K.; Weerasooriya, R. Ca2+ and SO42- interactions with dissolved organic matter: Implications of groundwater quality for CKDu incidence in Sri Lanka. J. Environ. Sci. 2020, 88, 326-337. [CrossRef]

19. Makehelwala, M.; Wei, Y.; Weragoda, S.K.; Weerasooriya, R.; Zheng, L. Characterization of dissolved organic carbon in shallow groundwater of chronic kidney disease affected regions in Sri Lanka. Sci. Total Environ. 2019, 660, 865-875. [CrossRef]

20. Hansima, M.A.C.K.; Makehelwala, M.; Jinadasa, K.B.S.N.; Wei, Y.; Nanayakkara, K.G.N.; Herath, A.C.; Weerasooriya, R. Fouling of ion exchange membranes used in the electrodialysis reversal advanced water treatment: A review. Chemosphere 2021, 263, 127951. [CrossRef]

21. APHA. Standard Methods for the Examination of Water and Wastewater, 19th ed.; Water Environment Federation: Alexandria, VA, USA; American Public Health Association: New York, NY, USA, 1995.

22. Jamaly, S.; Darwish, N.N.; Ahmed, I.; Hasan, S.W. A short review on reverse osmosis pretreatment technologies. Desalination 2014, 354, 30-38. [CrossRef]

23. Cooray, P.G. An Introduction to the Geology of Sri Lanka (Ceylon); National Museums of Sri Lanka Publication: Colombo, Sri Lanka, 1984; Volume 38.

24. Thivya, C.; Chidambaram, S.; Singaraja, C.; Thilagavathi, R.; Prasanna, M.V.; Anandhan, P.; Jainab, I. A study on the significance of lithology in groundwater quality of Madurai district, Tamil Nadu (India). Environ. Dev. Sustain. 2013, 15, 1365-1387. [CrossRef]

25. Zheng, L.; Cooray, T.; Zhong, H.; Weragoda, S.; Weerasooriyae, R.; Makehelwala, M.; Wei, Y. Critical challenges and solutions on ground drinking water in chronic kidney disease of unknown etiology (CKDu) affected regions in Sri Lanka. Chin. J. Environ. Eng. 2020, 14, 2100-2111. [CrossRef]

26. Tennakoon, T. Dental fluorosis in anuradhapura district, Sri Lanka. In Proceedings of the 4th International Workshop on Fluorosis Prevention and Defluoridation of Water, Colombo, Sri Lanka, 2-6 March 2004; pp. 19-22.

27. Ranasinghe, N.; Kruger, E.; Chandrajith, R.; Tennant, M. Groundwater fluoride in Sri Lanka: Opportunities to mitigate the risk at maximum contaminant level. Ceylon Med. J. 2018, 63, 174-179. [CrossRef] [PubMed]

28. Dharmaratne, R.W. Fluoride in drinking water and diet: The causative factor of chronic kidney diseases in the North Central Province of Sri Lanka. Environ. Health Prev. Med. 2015, 20, 237-242. [CrossRef] [PubMed]

29. Naidu, L.; Saravanan, S.; Manickam, C.; Goel, M.; Das, A.; Babu, J. Nanofiltration in transforming surface water into healthy water: Comparison with reverse osmosis. J. Chem. 2015, 2015, 1-6. [CrossRef] [PubMed]

30. Al-Amshawee, S.; Yunus, M.Y.B.M.; Azoddein, A.A.M.; Hassell, D.G.; Dakhil, I.H.; Hasan, H.A. Electrodialysis desalination for water and wastewater: A review. Chem. Eng. J. 2020, 380, 122231. [CrossRef]

31. Vingerhoeds, M.H.; Nijenhuis-de Vries, M.A.; Ruepert, N.; van der Laan, H.; Bredie, W.L.P.; Kremer, S. Sensory quality of drinking water produced by reverse osmosis membrane filtration followed by remineralisation. Water Res. 2016, 94, 42-51. [CrossRef]

32. Udeshani, W.A.C.; Dissanayake, H.M.K.P.; Gunatilake, S.K.; Chandrajith, R. Assessment of groundwater quality using water quality index (WQI): A case study of a hard rock terrain in Sri Lanka. Groundw. Sustain. Dev. 2020, 11. [CrossRef]

33. Hasson, D.; Bendrihem, O. Modeling remineralization of desalinated water by limestone dissolution. Desalination 2006, 190, 189-200. [CrossRef]

34. Vries, D.; Korevaar, M.; Ghanbari, S.; van Houwelingen, G.; van der Meer, W. Data fusion to monitor remineralisation of desalinated groundwater in calcite contactors. J. Water Process Eng. 2021, 41, 102011. [CrossRef]

35. Bason, S.; Oren, Y.; Freger, V. Ion transport in the polyamide layer of RO membranes: Composite membranes and free-standing films. J. Memb. Sci. 2011, 367, 119-126. [CrossRef]

36. Hao, X.; Gao, S.; Tian, J.; Sun, Y.; Cui, F.; Tang, C.Y. Calcium-carboxyl intrabridging during interfacial polymerization: A novel strategy to improve antifouling performance of thin film composite membranes. Environ. Sci. Technol. 2019, 53, 4371-4379. [CrossRef] 
37. Tiraferri, A.; Elimelech, M. Direct quantification of negatively charged functional groups on membrane surfaces. J. Memb. Sci. 2012, 389, 499-508. [CrossRef]

38. Tzotzi, C.; Pahiadaki, T.; Yiantsios, S.; Karabelas, A.; Andritsos, N. A study of CaCO 3 scale formation and inhibition in RO and NF membrane processes. J. Membr. Sci. 2007, 296, 171-184. [CrossRef]

39. Zhou, X.; Wang, Z.; Epsztein, R.; Zhan, C.; Li, W.; Fortner, J.D.; Pham, T.A.; Kim, J.-H.; Elimelech, M. Intrapore energy barriers govern ion transport and selectivity of desalination membranes. Sci. Adv. 2020, 6, eabd9045. [CrossRef]

40. Shen, M.; Keten, S.; Lueptow, R. Rejection mechanisms for contaminants in polyamide reverse osmosis membranes. J. Memb. Sci. 2016, 509. [CrossRef]

41. Chan, E.; Young, A.; Lee, J.-H.; Chung, J.; Stafford, C. Swelling of ultrathin crosslinked polyamide water desalination membranes J. Polym. Sci. B Polym. Phys. 2013, 51, 385-391. [CrossRef]

42. Dražević, E.; Kosutic, K.; Freger, V. Permeability and selectivity of reverse osmosis membranes: Correlation to swelling revisited. Water Res. 2013, 49. [CrossRef]

43. Tansel, B.; Sager, J.; Rector, T.; Garland, J.; Strayer, R.F.; Levine, L.; Roberts, M.; Hummerick, M.; Bauer, J. Significance of hydrated radius and hydration shells on ionic permeability during nanofiltration in dead end and cross flow modes. Sep. Purif. Technol. 2006, 51, 40-47. [CrossRef]

44. Sigurdardottir, S.B.; DuChanois, R.M.; Epsztein, R.; Pinelo, M.; Elimelech, M. Energy barriers to anion transport in polyelectrolyte multilayer nanofiltration membranes: Role of intra-pore diffusion. J. Memb. Sci. 2020, 603, 117921. [CrossRef]

45. Kiriukhin, M.Y.; Collins, K.D. Dynamic hydration numbers for biologically important ions. Biophys. Chem. 2002, 99, 155-168. [CrossRef]

46. Pandian, S.; Katha, A.R.; Moon, J.H.; Kolake, S.M.; Han, S. Exploring the effect of additives on polyamide membrane surface for seawater desalination using density functional tools. Desalination 2015, 367, 28-36. [CrossRef]

47. Freger, V. Ion partitioning and permeation in charged low-T* membranes. Adv. Colloid Interface Sci. 2020, 277, 102107. [CrossRef]

48. Park, H.G.; Kwon, Y.N. Investigation on the factors determining permeate $\mathrm{pH}$ in reverse osmosis membrane processes. Desalination 2018, 430, 147-158. [CrossRef]

49. Qin, J.-J.; Oo, M.; Lee, H.; Coniglio, B. Effect of feed $\mathrm{pH}$ on permeate $\mathrm{pH}$ and ion rejection under acidic conditions in NF process. J. Memb. Sci. 2004, 232, 153-159. [CrossRef]

50. Stenina, I.; Golubenko, D.; Nikonenko, V.; Yaroslavtsev, A. Selectivity of Transport Processes in Ion-Exchange Membranes: Relationship with the Structure and Methods for Its Improvement. Int. J. Mol. Sci. 2020, 21, 5517. [CrossRef] [PubMed]

51. Wright, S.H. Generation of resting membrane potential. Adv. Physiol. Educ. 2004, 28, 139-142. [CrossRef] [PubMed]

52. Haines, T.S.; Lloyd, J.W. Controls on silica in groundwater environments in the United Kingdom. J. Hydrol. 1985, 81, 277-295. [CrossRef] 